\title{
Lifetime Assessment of the NEXT Ion Thruster
}

Jonathan L. Van Noord

Glenn Research Center, Cleveland, Ohio 


\section{NASA STI Program . . . in Profile}

Since its founding, NASA has been dedicated to the advancement of aeronautics and space science. The NASA Scientific and Technical Information (STI) program plays a key part in helping NASA maintain this important role.

The NASA STI Program operates under the auspices of the Agency Chief Information Officer. It collects, organizes, provides for archiving, and disseminates NASA's STI. The NASA STI program provides access to the NASA Aeronautics and Space Database and its public interface, the NASA Technical Reports Server, thus providing one of the largest collections of aeronautical and space science STI in the world. Results are published in both non-NASA channels and by NASA in the NASA STI Report Series, which includes the following report types:

- TECHNICAL PUBLICATION. Reports of completed research or a major significant phase of research that present the results of NASA programs and include extensive data or theoretical analysis. Includes compilations of significant scientific and technical data and information deemed to be of continuing reference value. NASA counterpart of peer-reviewed formal professional papers but has less stringent limitations on manuscript length and extent of graphic presentations.

- TECHNICAL MEMORANDUM. Scientific and technical findings that are preliminary or of specialized interest, e.g., quick release reports, working papers, and bibliographies that contain minimal annotation. Does not contain extensive analysis.

- CONTRACTOR REPORT. Scientific and technical findings by NASA-sponsored contractors and grantees.
- CONFERENCE PUBLICATION. Collected papers from scientific and technical conferences, symposia, seminars, or other meetings sponsored or cosponsored by NASA.

- SPECIAL PUBLICATION. Scientific, technical, or historical information from NASA programs, projects, and missions, often concerned with subjects having substantial public interest.

- TECHNICAL TRANSLATION. Englishlanguage translations of foreign scientific and technical material pertinent to NASA's mission.

Specialized services also include creating custom thesauri, building customized databases, organizing and publishing research results.

For more information about the NASA STI program, see the following:

- Access the NASA STI program home page at http://www.sti.nasa.gov

- E-mail your question via the Internet to help@ sti.nasa.gov

- Fax your question to the NASA STI Help Desk at 443-757-5803

- Telephone the NASA STI Help Desk at 443-757-5802

- Write to: NASA Center for AeroSpace Information (CASI) 7115 Standard Drive Hanover, MD 21076-1320 


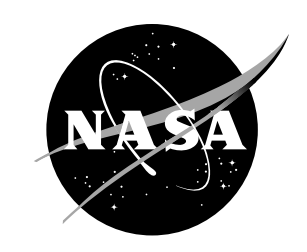

\section{Lifetime Assessment of the NEXT Ion Thruster}

Jonathan L. Van Noord

Glenn Research Center, Cleveland, Ohio

Prepared for the

43rd Joint Propulsion Conference and Exhibit

cosponsored by the AIAA, ASME, SAE, and ASEE

Cincinnati, Ohio, July 8-11, 2007

National Aeronautics and

Space Administration

Glenn Research Center

Cleveland, Ohio 44135 
Level of Review: This material has been technically reviewed by technical management.

Available from

NASA Center for Aerospace Information

7115 Standard Drive

Hanover, MD 21076-1320
National Technical Information Service 5301 Shawnee Road Alexandria, VA 22312

Available electronically at http://gltrs.grc.nasa.gov 


\title{
Lifetime Assessment of the NEXT Ion Thruster
}

\author{
Jonathan L. Van Noord \\ National Aeronautics and Space Administration \\ Glenn Research Center \\ Cleveland, Ohio 44135
}

\begin{abstract}
Ion thrusters are low thrust, high specific impulse devices with required operational lifetimes on the order of 10,000 to 100,000 hr. The NEXT ion thruster is the latest generation of ion thrusters under development. The NEXT ion thruster currently has a qualification level propellant throughput requirement of $450 \mathrm{~kg}$ of xenon, which corresponds to roughly $22,000 \mathrm{hr}$ of operation at the highest throttling point. Currently, a NEXT engineering model ion thruster with prototype model ion optics is undergoing a long duration test to determine wear characteristics and establish propellant throughput capability. The NEXT thruster includes many improvements over previous generations of ion thrusters, but two of its component improvements have a larger effect on thruster lifetime. These include the ion optics with tighter tolerances, a masked region and better gap control, and the discharge cathode keeper material change to graphite. Data from the NEXT $2000 \mathrm{hr}$ wear test, the NEXT long duration test, and further analysis is used to determine the expected lifetime of the NEXT ion thruster. This paper will review the predictions for all of the anticipated failure mechanisms. The mechanisms will include wear of the ion optics and cathode's orifice plate and keeper from the plasma, depletion of low work function material in each cathode's insert, and spalling of material in the discharge chamber leading to arcing. Based on the analysis of the NEXT ion thruster, the first failure mode for operation above a specific impulse of $2000 \mathrm{sec}$ is expected to be the structural failure of the ion optics at $750 \mathrm{~kg}$ of propellant throughput, 1.7 times the qualification requirement. An assessment based on mission analyses for operation below a specific impulse of $2000 \mathrm{sec}$ indicates that the NEXT thruster is capable of double the propellant throughput required by these missions.
\end{abstract}

\section{Nomenclature}

$A_{B} \quad$ beamlet cross sectional area

$C \quad$ general constant

e elementary charge

$F \quad$ thrust

$I_{B} \quad$ beam current

$I_{c x} \quad$ charge exchange ion production current

$I_{e} \quad$ discharge current

$I_{s p} \quad$ specific impulse

$I^{++} / I^{+}$ratio of doubly to singly charged ions

$j_{b, \text { peak }}$ peak beam current density

$J_{N K} \quad$ neutralizer keeper current

$l_{n} \quad$ neutralization length

$\dot{m} \quad$ total mass flow rate

$\dot{m}_{d c}$ in mass flow rate into discharge chamber

$n_{o} \quad$ neutral density

$n_{+} \quad$ ion density 


$\begin{array}{ll}P_{i n-P P U} & \text { power into power processing unit } \\ R & \text { ratio of net to total accelerating voltage } \\ V_{a} & \text { accelerator grid voltage } \\ V_{b p s} & \text { beam power supply voltage } \\ v_{i} & \text { ion velocity } \\ V_{N E T} & \text { beam net accelerating voltage } \\ v_{o} & \text { neutral velocity } \\ V o l & \text { volume of the charge exchange production region } \\ Y & \text { sputter yield } \\ \beta & \text { constant based on ion mass } \\ \gamma & \text { sputter rate } \\ \sigma_{c x} & \text { ion charge exchange cross section } \\ \phi_{s g} & \text { screen grid ion transparency }\end{array}$

\section{Introduction}

NASA's Evolutionary Xenon Thruster (NEXT) project encompasses the development of a high performance, nominal 7-kW, Electric Propulsion Thruster (EPT); a light weight, high efficiency power processing unit (PPU); a highly flexible advanced Propellant Management System (PMS); and a lightweight, low-cost gimbal (Refs. 1 and 2). The goal of the NEXT project is to develop the next generation ion propulsion technology to NASA Technology Readiness Level (TRL) 6 (Ref. 3). The NEXT project has built on knowledge gained from the current state-of-the-art NASA Solar Electric Propulsion Technology Application Readiness (NSTAR) thruster system to create a more efficient, higher specific impulse, and lower specific mass system (Ref. 2). The design approach will provide future NASA science missions with the greatest value in mission performance at a low total development cost.

The NEXT thruster is a $36 \mathrm{~cm}$ beam diameter, 2-grid ion optics, xenon ion thruster that uses an input power of 0.54-6.9 $\mathrm{kW}$ and has a maximum specific impulse of over $4100 \mathrm{sec}$ and a maximum thrust greater than $230 \mathrm{mN}$ (Ref. 2). A throttle table containing several of the operating points for the NEXT thruster is given in Table 1. Several potential missions have been evaluated using the NEXT thruster (Ref. 4). These missions included a Saturn mission, Neptune mission, a near Earth asteroid return, comet rendezvous, Vesta-Ceres rendezvous, Titan direct lander, and a comet surface sample return. A $300 \mathrm{~kg}$ xenon throughput requirement, which corresponds to a $1.23 \times 10^{7} \mathrm{~N}$-s total impulse, is derived from these studies with a corresponding $450 \mathrm{~kg}$ qualification level (Ref. 1). This paper will provide an assessment of the anticipated lifetime of the NEXT thruster components and demonstrate that the NEXT thruster will fulfill the mission propellant throughput requirements.

Previous extended testing by the NSTAR program examined the wear mechanisms for ion thrusters (Refs. 5, 6, 7 and 8). Several of these wear mechanisms were minimized and mitigated during the NSTAR program, but a set of life-limiting mechanisms was established. Based on these related failure modes, an initial life assessment of the NEXT thruster was prepared during Phase I of the NEXT program (Ref. 9). The relevant failure modes evaluated in this study are shown in Table 2. To date several iterations of life models have been utilized based on the most recent data available for the NEXT thruster. These have included deterministic models for the ion optics (Refs. 10, 11, and 12) and the hollow cathodes (Refs. 9 and 13). Modeling of the thruster was also accomplished using a probabilistic failure analysis (PFA) process described in Reference 14. To date, PFA modeling uncertainties have led to unrealistic results that are not supported by test data. Until these uncertainties are resolved, PFA is of limited value. Further work is continuing to reduce these uncertainties, such as measurement of the grid gap during extended operation (Refs. 15 and 16). 
TABLE 1.-NEXT THROTTLE TABLE: DEMONSTRATED THRUSTER

\begin{tabular}{|c|c|c|c|c|c|c|c|c|}
\hline \multicolumn{9}{|c|}{ AND PPU PERFORMANCE AT BEGINNING OF LIFE } \\
\hline & $\begin{array}{l}V_{b p s}, \\
\mathrm{~V}\end{array}$ & $\begin{array}{l}F \\
\mathrm{mN}\end{array}$ & $\begin{array}{l}I_{s p} \\
\text { sec }\end{array}$ & $\begin{array}{c}P_{\text {in- } P P U}, \\
\mathrm{~kW}\end{array}$ & $\begin{array}{c}I_{e} \\
\mathrm{~A}\end{array}$ & $\begin{array}{l}V_{a}, \\
\mathrm{~V}\end{array}$ & $\mathrm{I}^{++} / \mathrm{I}^{+}$ & $\begin{array}{c}J_{N K}, \\
\mathrm{~A}\end{array}$ \\
\hline \multirow{4}{*}{$\begin{array}{c}\dot{m}=5.76 \mathrm{mg} / \mathrm{sec} \\
I_{B}=3.52 \mathrm{~A}\end{array}$} & 1800 & 236 & 4190 & 7.220 & 18.20 & -210 & 0.045 & 3.0 \\
\hline & 1567 & 221 & 3910 & 6.385 & 18.83 & -210 & 0.045 & 3.0 \\
\hline & 1396 & 208 & 3690 & 5.780 & 19.30 & -210 & 0.045 & 3.0 \\
\hline & 1179 & 192 & 3395 & 4.965 & 19.91 & -200 & 0.045 & 3.0 \\
\hline \multirow{4}{*}{$\begin{array}{c}\dot{m}=5.12 \mathrm{mg} / \mathrm{sec} \\
I_{B}=3.10 \mathrm{~A}\end{array}$} & 1800 & 208 & 4150 & 6.390 & 16.48 & -210 & 0.045 & 3.0 \\
\hline & 1567 & 194 & 3875 & 5.660 & 17.03 & -210 & 0.045 & 3.0 \\
\hline & 1396 & 184 & 3660 & 5.085 & 17.44 & -210 & 0.045 & 3.0 \\
\hline & 1179 & 169 & 3360 & 4.490 & 17.98 & -200 & 0.045 & 3.0 \\
\hline \multirow{5}{*}{$\begin{array}{c}\dot{m}=4.46 \mathrm{mg} / \mathrm{sec} \\
I_{B}=2.70 \mathrm{~A}\end{array}$} & 1800 & 181 & 4150 & 5.600 & 14.72 & -210 & 0.045 & 3.0 \\
\hline & 1567 & 169 & 3875 & 4.920 & 15.20 & -210 & 0.045 & 3.0 \\
\hline & 1396 & 160 & 3660 & 4.455 & 15.56 & -210 & 0.045 & 3.0 \\
\hline & 1179 & 147 & 3360 & 3.860 & 16.03 & -200 & 0.045 & 3.0 \\
\hline & 1021 & 137 & 3125 & 3.425 & 16.41 & -175 & 0.045 & 3.0 \\
\hline \multirow{5}{*}{$\begin{array}{c}\dot{m}=3.92 \mathrm{mg} / \mathrm{sec} \\
I_{B}=2.35 \mathrm{~A}\end{array}$} & 1800 & 158 & 4100 & 4.870 & 13.14 & -210 & 0.045 & 3.0 \\
\hline & 1567 & 147 & 3830 & 4.315 & 13.57 & -210 & 0.045 & 3.0 \\
\hline & 1396 & 139 & 3615 & 3.910 & 13.87 & -210 & 0.045 & 3.0 \\
\hline & 1179 & 128 & 3325 & 3.390 & 14.28 & -200 & 0.045 & 3.0 \\
\hline & 1021 & 119 & 3090 & 3.010 & 14.61 & -175 & 0.045 & 3.0 \\
\hline \multirow{5}{*}{$\begin{array}{c}\dot{m}=3.16 \mathrm{mg} / \mathrm{sec} \\
I_{B}=2.00 \mathrm{~A}\end{array}$} & 1800 & 134 & 4310 & 4.235 & 13.88 & -210 & 0.063 & 3.0 \\
\hline & 1567 & 125 & 4025 & 3.760 & 14.12 & -210 & 0.063 & 3.0 \\
\hline & 1396 & 118 & 3800 & 3.415 & 14.35 & -210 & 0.063 & 3.0 \\
\hline & 1179 & 108 & 3490 & 2.970 & 14.72 & -200 & 0.063 & 3.0 \\
\hline & 1021 & 101 & 3250 & 2.620 & 15.07 & -175 & 0.063 & 3.0 \\
\hline \multirow{5}{*}{$\begin{array}{c}\dot{m}=2.60 \mathrm{mg} / \mathrm{sec} \\
I_{B}=1.60 \mathrm{~A}\end{array}$} & 1800 & 107 & 4190 & 3.460 & 12.45 & -210 & 0.063 & 3.0 \\
\hline & 1567 & 99.9 & 3910 & 3.080 & 12.65 & -210 & 0.063 & 3.0 \\
\hline & 1396 & 94.3 & 3690 & 2.765 & 12.83 & -210 & 0.063 & 3.0 \\
\hline & 1179 & 86.7 & 3395 & 2.415 & 13.13 & -200 & 0.063 & 3.0 \\
\hline & 1021 & 80.6 & 3155 & 2.160 & 13.40 & -175 & 0.063 & 3.0 \\
\hline \multirow{11}{*}{$\begin{array}{c}\dot{m}=2.05 \mathrm{mg} / \mathrm{sec} \\
I_{B}=1.20 \mathrm{~A}\end{array}$} & 1800 & 80.2 & 4000 & 2.585 & 8.36 & -210 & 0.063 & 3.0 \\
\hline & 1567 & 74.9 & 3735 & 2.300 & 8.50 & -210 & 0.063 & 3.0 \\
\hline & 1396 & 70.7 & 3525 & 2.090 & 8.62 & -210 & 0.063 & 3.0 \\
\hline & 1179 & 65.0 & 3240 & 1.825 & 8.83 & -200 & 0.063 & 3.0 \\
\hline & 1021 & 60.4 & 3015 & 1.635 & 9.02 & -175 & 0.063 & 3.0 \\
\hline & 936 & 57.8 & 2885 & 1.520 & 9.15 & -150 & 0.063 & 3.0 \\
\hline & 850 & 55.1 & 2745 & 1.415 & 9.29 & -125 & 0.063 & 3.0 \\
\hline & 679 & 49.2 & 2450 & 1.210 & 9.54 & -115 & 0.063 & 3.0 \\
\hline & 650 & 48.1 & 2400 & 1.175 & 9.54 & -144 & 0.063 & 3.0 \\
\hline & 400 & 37.2 & 1855 & 0.865 & 9.54 & -394 & 0.063 & 3.0 \\
\hline & 300 & 31.8 & 1585 & 0.740 & 9.49 & -525 & 0.063 & 3.0 \\
\hline $\begin{array}{c}\dot{m}=1.85 \mathrm{mg} / \mathrm{sec} \\
I_{B}=1.00 \mathrm{~A}\end{array}$ & 275 & 25.5 & 1400 & 0.610 & 7.99 & -500 & 0.038 & 3.0 \\
\hline
\end{tabular}

Several tests of the NEXT thruster and its components to evaluate wear mechanisms have already been completed. The NEXT Engineering Model 1 (EM1) thruster was wear-tested for $2038 \mathrm{hr}$ (43 kg of xenon throughput) to evaluate thruster wear (Ref. 17). Two wear mechanisms were revealed that could potentially lead to a premature failure. One was the excessive wear on the discharge cathode keeper orifice plate and the other was excessive wear on the accelerator grid holes beyond a radius of $15.3 \mathrm{~cm}$. While loss of the keeper orifice plate does not result in thruster failure, it does protect the cathode and extend its life. The keeper material was changed to graphite for subsequent designs to achieve significant margin for life. The ion optics design was modified by removing some of the outer holes and making the effective beam diameter $36 \mathrm{~cm}$ instead of the previous $40 \mathrm{~cm}$. The removal of holes was only in regions of low plasma density resulting in effectively similar discharge losses without the added optics wear. 
TABLE 2.-SUMMARY OF CREDIBLE ION THRUSTER FAILURE MODES

\begin{tabular}{|l|l|}
\hline \multicolumn{1}{|c|}{ Component } & \multicolumn{1}{c|}{ Wear mechanism } \\
\hline Discharge cathode & $\begin{array}{l}\text { Insert barium depletion resulting in inability to ignite or excessive temperatures } \\
\text { Wear of orifice plate causing structural failure } \\
\text { Wear of keeper orifice plate resulting in exposure of cathode orifice plate and heater }\end{array}$ \\
\hline Neutralizer cathode & $\begin{array}{l}\text { Insert barium depletion resulting in inability to ignite or excessive temperatures } \\
\text { Excessive wear of orifice plate } \\
\text { Wear of keeper tube exposing cathode tube and heater } \\
\text { Neutralizer orifice clogging preventing proper cathode operation }\end{array}$ \\
\hline Cathode heaters & Mechanical failure from cyclic operation \\
\hline Accelerator grid & $\begin{array}{l}\text { Pit and groove wear from charge exchange ions that result in structural failure } \\
\text { Aperture enlargement resulting in electron backstreaming }\end{array}$ \\
\hline Screen grid & Upstream wear from impinging ions \\
\hline Ion optics assembly & An unclearable short between grids from debris present during launch or spalled material from wear \\
\hline Discharge chamber & $\begin{array}{l}\text { Poor flake retention of sputtered material resulting in optics arcing } \\
\text { Magnet temperatures excessive resulting in field degradation }\end{array}$ \\
\hline Insulators and HVPI's & Degrading voltage standoff from extended operation at elevated temperature \\
\hline
\end{tabular}

Currently, the NEXT Engineering Model 3 (EM3) is undergoing a long duration test (LDT) at the NASA Glenn Research Center (Refs. 15 and 16) The intent of this test is to validate and qualify the NEXT propellant throughput capability at the highest power throttling point to a qualification-level of $450 \mathrm{~kg}$. The operation to date has been at a beam power supply voltage of $1800 \mathrm{~V}$ and a beam current of $3.52 \mathrm{~A}$. Currently, EM3 has processed $207 \mathrm{~kg}$ of xenon and operated for 10,100 hr. As the data from this test continues to become available, it will be incorporated into the life assessment.

The purpose of this document is to provide a summary of the life assessment for the NEXT ion thruster and its various components. This assessment will continue to evolve with time based on the latest test data and modeling, but this study represents the best understanding of the anticipated life of the thruster and its components. Table 2 contains a list of credible ion thruster failure mechanisms that will be examined in this paper. A review of previous ion thruster endurance tests along with the causes of failure is given in Reference 18 .

\section{Service Life Assessment of the NEXT Thruster}

\section{NEXT Discharge Cathode Lifetime}

The discharge cathode provides the electrons to ionize the propellant gas. The discharge cathode is a refractory metal tube containing an impregnated porous tungsten insert with a low work function material for electron emission at reduced operating temperatures. It is commonly referred to as a hollow cathode. A swaged heater is used initially for discharge ignition, but once ignition occurs, the insert is self-heated by the plasma. The hollow cathode is enclosed in a keeper that protects the cathode from the plasma contained in the discharge chamber. The discharge cathode has multiple mechanisms that affect its lifetime. One mechanism is the depletion of the insert impregnated material resulting in an increased work function. This would lead to significantly higher insert temperatures, higher discharge voltages, and potential difficulty in ignition. Another lifetime mechanism is excessive wear of the cathode and keeper orifice plates from impinging ions. Significant wear of the cathode orifice plate would be preceded by the keeper orifice plate eroding sufficiently to expose the cathode orifice plate. The cathode orifice plate could then be eroded to the point of compromising welds, losing the orifice plate, and sputter erosion of the sheathed heater causing it to fail and prevent further ignitions. These lifetime mechanisms will be evaluated in the following sections. 


\section{Insert Barium Depletion}

There are two primary factors that determine the life of an impregnated insert in the hollow cathode. They include the formation of tungstates, which could bind up the barium impregnate and inhibit diffusion, and depletion of barium impregnate from the insert (Ref. 19). The current hollow cathode life models are either based on predictions of chemical processes and vapor pressures (Refs. 13 and 20), or on lifetime data from planar impregnated cathodes operated in a vacuum tube (Ref. 21). The chemistry-based model is limited due to the shear complexity of the chemical processes at the insert and the limited high temperature chemistry data in the model. There are lifetime data compiled for planar impregnated cathodes used in vacuum tubes (Ref. 22), however, due to the different operating environments and mechanical designs (cylindrically enclosed versus planar) it is unclear how well the planar vacuum data and life models transport to a hollow cathode. In all of these models, however, emitter temperature is the major factor for determining the insert's lifetime (Refs. 19 and 23) The approach here will be to use the planar impregnated cathode model relationship between insert temperature and lifetime while confirming its results with previous cathode life tests.

This model is based significantly on temperature and life data of the planar impregnated cathodes derived from a relationship outlined by Palluel and Shroff (Ref. 23). These cathodes were operated in a vacuum environment. The model examined the relationship between temperature, barium depletion depth and lifetime for impregnated planar cathodes that are used in the vacuum industry. These relationships are then used to estimate hollow cathode emitter lifetime based on temperature and insert thickness (Ref. 21). While it appears possible that barium removal may not be significantly affected by the plasma environment of the hollow cathode compared to the vacuum environment (Ref. 24), it is still uncertain to what degree the negative impact on life would be from the tungstates that form (Ref. 19), or the positive impact on life that results from the reuse of barium by effectively enclosing the insert in the cathode tube (Ref. 20).

To establish the credibility of any model, it is important to compare the results to known data. For a hollow cathode insert, it is important to establish a maximum depth that barium can be depleted and yet efficiently emit electrons. At the completion of the NSTAR Extended Life Test (ELT), the thruster operated for more than $30+\mathrm{khr}$ and both the neutralizer and discharge cathodes were still operational (Ref. 5). Measurements were taken to determine barium depletion in the insert to a depth of $500 \mu \mathrm{m}$. The ELT results showed some barium depletion at depths of 100 and $300 \mu \mathrm{m}$ at the downstream end of the insert in the discharge chamber cathode, but not at $500 \mu \mathrm{m}$. So a cathode should operate adequately with barium depletion depths of at least $300 \mu \mathrm{m}$.

Another hollow cathode was tested at $12 \mathrm{~A}$ of emission current for $28 \mathrm{khr}$ before it failed to ignite (Ref. 25). The peak insert temperature measured on a similar cathode was $1180{ }^{\circ} \mathrm{C}$ at $12 \mathrm{~A}$ of emission current (Ref. 26). Using that peak temperature and an estimated depletion depth of $500 \mu \mathrm{m}$, the model outlined in References 21 and 23 yields a lifetime estimate of $30 \mathrm{khr}$. While it is difficult to draw further conclusions when only one test was compared to the model, it does lend credence to the model and a rational for a barium depletion depth of $500 \mu \mathrm{m}$ resulting in end of insert life, which is consistent with the NSTAR ELT results.

The useful life of the NEXT cathode inserts (both discharge and neutralizer) was calculated. The inserts were assumed to only have a thickness of $500 \mu \mathrm{m}$ to extract barium, even though the actual thickness is larger. Peak insert temperature is the other parameter needed for the model. Currently, no insert temperature measurements are available for the NEXT insert, but orifice plate temperatures have been measured on a cathode similar to the discharge cathode and are shown in Figure 1. These temperatures were measured using a planar anode configuration. The cathode insert lifetime model uses the depletion depth and peak temperature to produce a lifetime estimate in hours for a particular discharge current. Based on the NEXT throttle table, the peak cathode emission current would be $20 \mathrm{~A}$. This corresponds to an orifice plate temperature of at most $1030^{\circ} \mathrm{C}$, as shown in Figure 1. It has been shown that the emitter on a cathode can be up to $90{ }^{\circ} \mathrm{C}$ cooler (Ref. 26) or $100{ }^{\circ} \mathrm{C}$ hotter (Ref. 27) than the orifice plate temperature. For the purposes of this study, the lifetime results are shown over $\mathrm{a} \pm 100{ }^{\circ} \mathrm{C}$ 


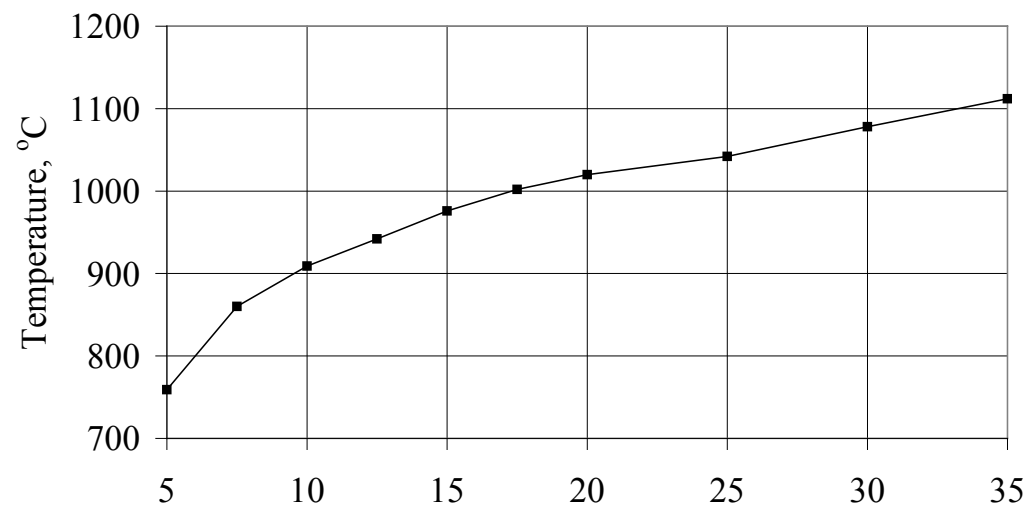

Anode Current, A

Figure 1.-Orifice plate temperatures measured on a cathode similar to the NEXT discharge cathode.

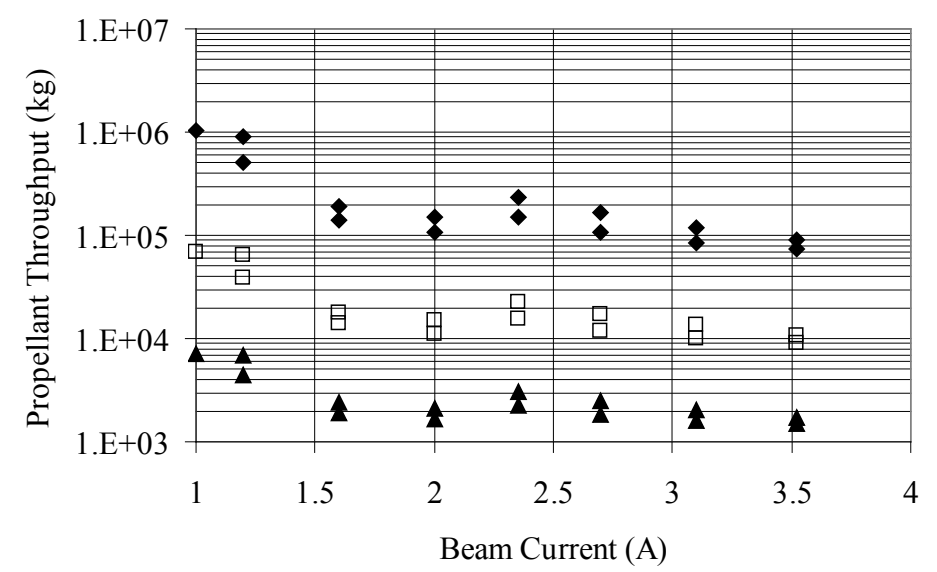

- Peak Insert Temp. $=$ Orifice Plate Temp. $-100^{\circ} \mathrm{C}$

$\square$ Peak Insert Temp. $=$ Orifice Plate Temp.

$\Delta$ Peak Insert Temp. $=$ Orifice Plate Temp.$+100^{\circ} \mathrm{C}$

Figure 2.-Discharge cathode propellant throughput capability for a given beam current. The numerous data points at given beam current are due to different discharge currents required for different beam voltages.

temperature span on the orifice plate temperatures. Using the NEXT throttle table as shown in Table 1, the discharge current can be related to the beam current, and the cathode lifetime in hours can be converted to a thruster propellant throughput. Using results from the planar cathode life data, the prediction of thruster cathode emitter lifetime in kilograms of xenon throughput for a particular beam current is shown in Figure 2. The least amount of propellant throughput for the NEXT thruster is at a $3.52 \mathrm{~A}$ beam current and results in an insert lifetime of at least $1000 \mathrm{~kg}$ xenon throughput, which is over two times the qualification requirement. This would correspond to an insert temperature around $1130{ }^{\circ} \mathrm{C}$ and the lifetime of $48 \mathrm{khr}$. As the beam current decreases, the expected lifetime of the insert will increase.

\section{Keeper Wear}

The main purpose of the cathode keeper is to protect the cathode from excessive erosion due to ion impingement from the discharge plasma. Early in the NSTAR program, the thruster was wear-tested without a keeper and severe erosion of the cathode orifice plate and heater occurred (Ref. 7). Subsequent to that test, a sacrificial keeper was added to protect the cathode (Ref. 8). Once the keeper is sufficiently eroded to constitute its end of life, the cathode and heater are exposed and their erosion rates dramatically increase, but the keeper end of life would not result in the end of life of the thruster. In this study, keeper erosion to the point of exposing the cathode and heater will be conservatively considered a failure.

Previously, the NEXT discharge keeper service life had been analyzed based on the NSTAR ELT test findings (Ref. 28). This model and analysis were completed with some component level testing and prior 
to any wear test of a NEXT thruster. The assessment determined that the keeper should last a minimum of $375 \mathrm{~kg}$ of xenon throughput and possibly up to $844 \mathrm{~kg}$. However, during the NEXT $2000 \mathrm{hr}$ wear test, higher than anticipated keeper wear was found (Ref. 17). The cross section of the keeper after the test is shown in

Figure 3. The wear profile can be seen and the maximum thickness eroded is roughly at a radius of 40 percent of the total keeper radius. This profile is similar to those of previous thruster tests (Ref. 6). The maximum keeper erosion from the NEXT $2000 \mathrm{hr}$ test was measured to be about 15 percent of the keeper orifice plate thickness. With the conservative assumption that the eroded depth exhibited in that valley would be linear with time, the keeper orifice plate propellant throughput capability was estimated to be $280 \mathrm{~kg}$. While this would not constitute a thruster failure, it allows for excessive erosion of the cathode orifice plate and heater to occur sooner than desired. To ensure ample lifetime, the discharge keeper material was changed to graphite, which has a sputter yield that is about 15 percent of the original material.

To predict the discharge keeper lifetime, a new keeper erosion model has been developed. Currently, the model is based on erosion profiles from wear tests and attempts to evaluate the angular impact of ions on the keeper face. The primary assumption of this model is that the ions wearing the keeper originate from an effective point source, which is depicted in Figure 4. This assumption is not fully validated by experimentation, but the model does demonstrate that the wear pattern could be caused by angular dependence of the impinging ion. The model assumes that the ion current density on the keeper drops by the square of the distance from this point source and the total current to the keeper must equal the measured ion current. The ion current also is assumed to have a fixed ratio of doubly and singly charged ions. Another assumption used is the angular dependence of wear based on the angle of impact from a xenon ion originating from the point source onto the keeper surface. Currently, the angular dependence is based on the lowest measured energy profile available of $78 \mathrm{eV}$ xenon ions and is shown in Figure 5 . This profile is then scaled down to provide the sputter yield as a function of impact angle for lower ion energies. Xenon ions impact the keeper at energies around 25 and $50 \mathrm{eV}$ for singly and doubly charged ions, respectively. Ions with energies of 25 and $50 \mathrm{eV}$ have normal sputtering yields approximately 0.5 to 50 percent of the $78 \mathrm{eV}$ ions, respectively (Ref. 29). This model cannot determine the relative amounts of singly or doubly charged ions causing the wear, so only a single bulk sputter yield will be used to represent their net effect. The model does not incorporate additional physical parameters such as electric and magnetic fields, so it cannot predict the point source location a priori. This requires a fit to experimental wear data in order to predict the wear rate with time.

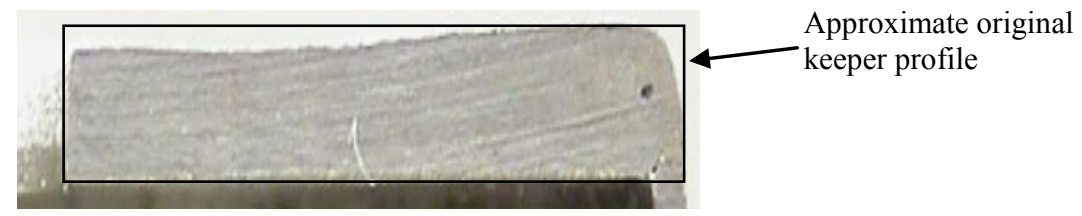

Figure 3.-NEXT keeper orifice cross-section. Picture aspect ratio is changed to exaggerate wear profile.

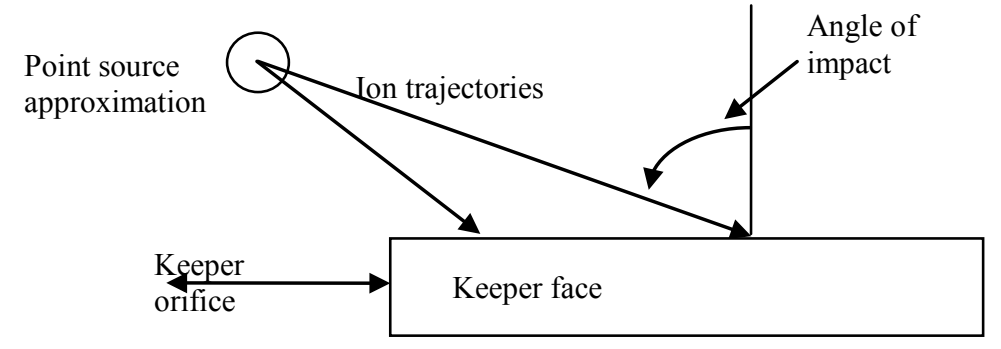

Figure 4.-Picture depicting ion point source approximation for keeper wear model. 


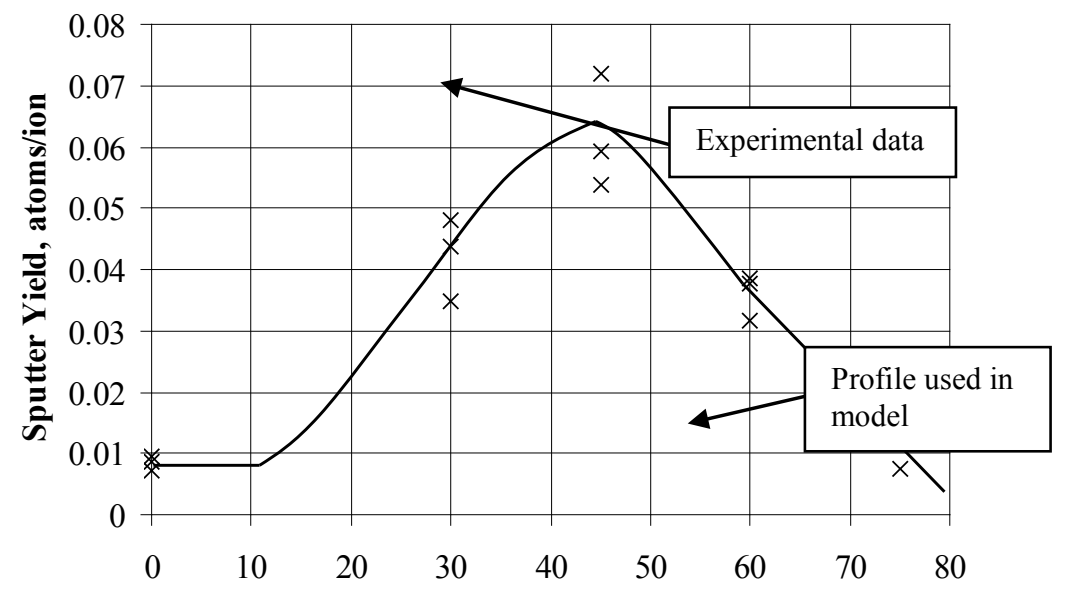

Ion Impact Angle, degree

Figure 5.-Data showing the angular dependence of sputter yield for $78 \mathrm{eV}$ xenon ions impacting on molybdenum (Ref. 30).

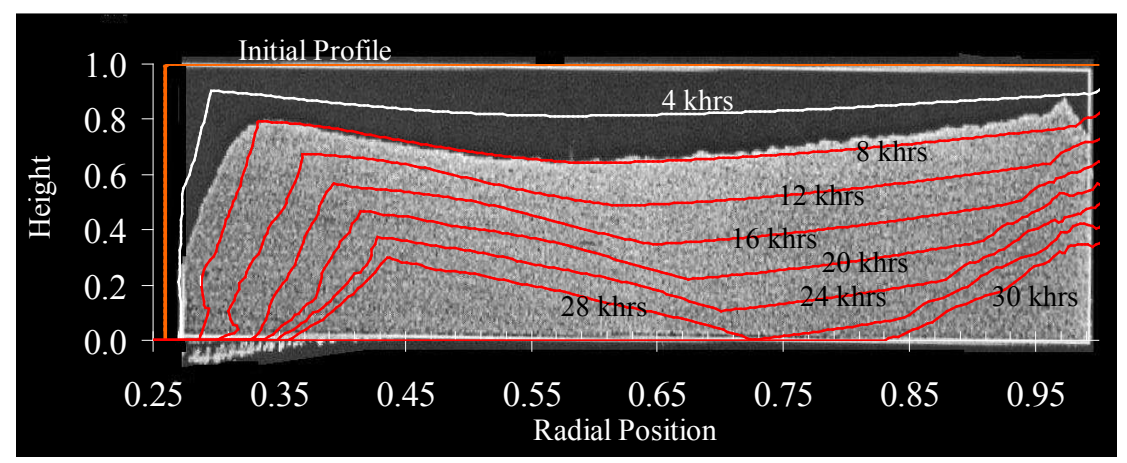

Figure 6.-Comparison of keeper wear model predictions to NSTAR $8200 \mathrm{hr}$ test keeper cross-section.

The results of the model for the NSTAR keeper are shown in Figure 6. The keeper cross section shown is from the NSTAR $8200 \mathrm{hr}$ test (Ref. 6). It is assumed that $0.2 \mathrm{~A}$ of ion current is collected by the keeper (Ref. 31). The sputter yield values used to produce Figure 6 had a normal value of $2.3 \times 10^{-5}$ atoms/ion, which is 0.27 percent the values that are shown in Figure 5. If there were only singly charged xenon ions, this normal sputter yield would correspond to ions with an energy around $20 \mathrm{eV}$ (Ref. 29). This calculated ion energy corresponds roughly to a plasma potential of $25 \mathrm{eV}$ (assuming the keeper is around $5 \mathrm{~V}$ of cathode potential) and demonstrates feasibility of the model since plasma potentials have been measured near the cathodes to a range of 10 to $30 \mathrm{eV}$ (Ref. 32).

The predicted keeper downstream profiles shown in Figure 6 indicate a reasonable correlation and that the angular dependence of the impacting xenon ion on the keeper could be a significant factor when estimating a keeper's wear and lifetime. Additional work is needed to improve the predictions on the inner diameter of the orifice region. It is possible that the point source will retreat towards the keeper once it begins eroding and increase the erosion closer to the orifice. Likely, the orifice will erode open faster than predicted after $\sim 16 \mathrm{khr}$ once a conical shape is established in the entire orifice region. A majority of the keeper is predicted to be worn away after $28 \mathrm{khr}$ of operation as shown in Figure 6 . Unfortunately, the keeper orifice wear exhibited during the NSTAR ELT does not offer useful data to compare to the model's wear prediction since a cathode to keeper electrical short occurred early during the test that resulted in accelerated erosion (Ref. 33). It is valuable to note that even with the increased erosion during the test penetration through the face of the keeper was never observed. 
The model was then used to predict the wear on the NEXT molybdenum keeper. The model comparison to the NEXT $2000 \mathrm{hr}$ wear results is shown in Figure 7. Based on measurements, the keeper ion current was 0.225 A during that test (Ref. 31). Excellent agreement is seen on the keeper face profile with the profilometry data taken after the $2000 \mathrm{hr}$ wear test. It is expected that with additional time, the region inside the 0.5 radius location will erode faster than the model predicts. Then, just as with the NSTAR keeper, the erosion through the entire keeper thickness will progress from the orifice out. To fit the experimental wear data, the sputter yield values used had a normal value of $3.4 \times 10^{-5}$ atoms/ion and were 0.4 percent of the values shown in Figure 5. If there were only singly charged xenon ions, the normal sputter yield could correspond to an ion energy of around $22 \mathrm{eV}$ (Ref. 29). This value again shows that the model is predicting feasible results. The prediction is that the keeper would erode to expose the heater after approximately $18 \mathrm{khr}$ of operation. This would correspond to $380 \mathrm{~kg}$ of xenon throughput and agrees with a pretest prediction of $375 \mathrm{~kg}$ (Ref. 17). This is less that than the $450 \mathrm{~kg}$ throughput qualification level, but does not constitute an end of life, rather the point at which the heater would be exposed to the plasma and experience increased wear.

An effort is continuing to improve the keeper model and apply it to the NEXT graphite keeper. Concurrent to the development of the model, the decision was made in the NEXT project to change to keeper material to graphite in order to substantially lower the sputtering yield and ensure adequate lifetime. The effect of the change to graphite on the volumetric wear can be determined based on the equations described in Reference 28. The change in volumetric wear of the keeper is determined by the ratio of the effective yield of the materials based on singly and doubly charged ions, the keeper's mass, and its density. The sputtering yield values for molybdenum and carbon can be found in Reference 29 . The resulting volumetric wear rate for the molybdenum keeper is about 6.5 times the rate for the graphite keeper.

There are limited low energy angular sputter data for graphite to predict the angular change from molybdenum. The model used a similar angular dependence as molybdenum to predict the graphite keeper wear, but with a magnitude that is 6.5 times less. The predicted propellant throughput using a graphite keeper would be in excess of $117 \mathrm{khr}$, which is $2400 \mathrm{~kg}$ Xe throughput -5.3 times qualification requirement for thruster throughput of $450 \mathrm{~kg}$, as shown in Figure 8. This provides significant margin for life. One of the few thruster wear tests to utilize a graphite keeper was the Herakles precursor engine HiPEP. During its $2000 \mathrm{hr}$ test, minimal wear on the keeper was found. In fact, what appears to be machining marks were still visible (Ref. 34). Using the 6.5 times erosion rate difference, the NEXT keeper would only have exhibited around 2 percent thickness reduction in the NEXT $2000 \mathrm{hr}$ test if it had been graphite. While a change in keeper orifice plate thickness cannot be determined in situ, the NEXT LDT graphite keeper orifice has shown no measurable wear as of $207 \mathrm{~kg}$ xenon throughput and 10,100 hr of operation (Ref. 15).

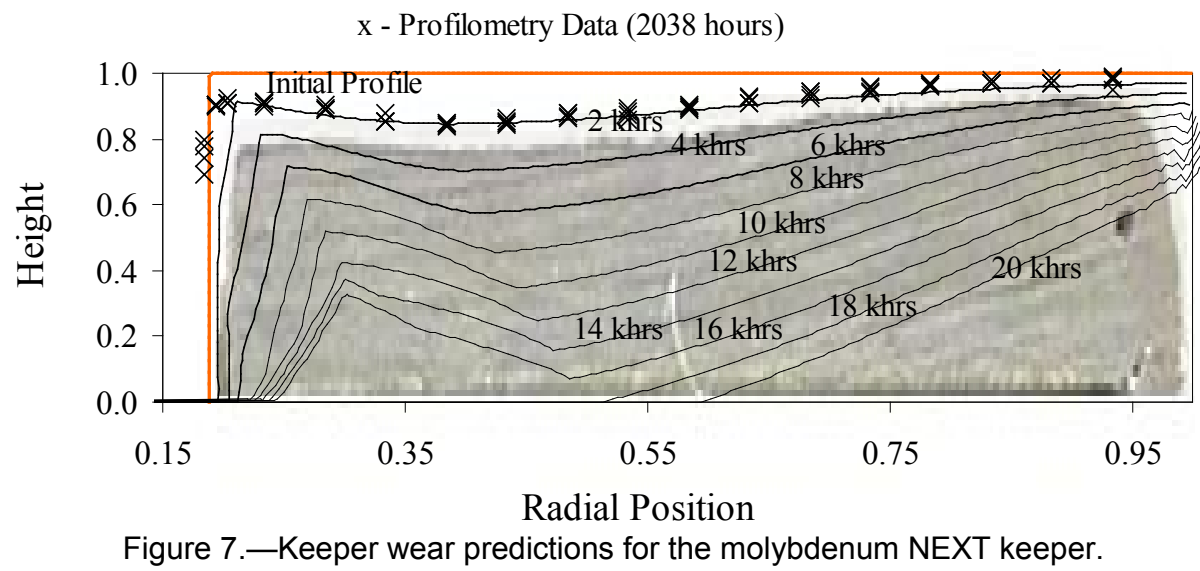




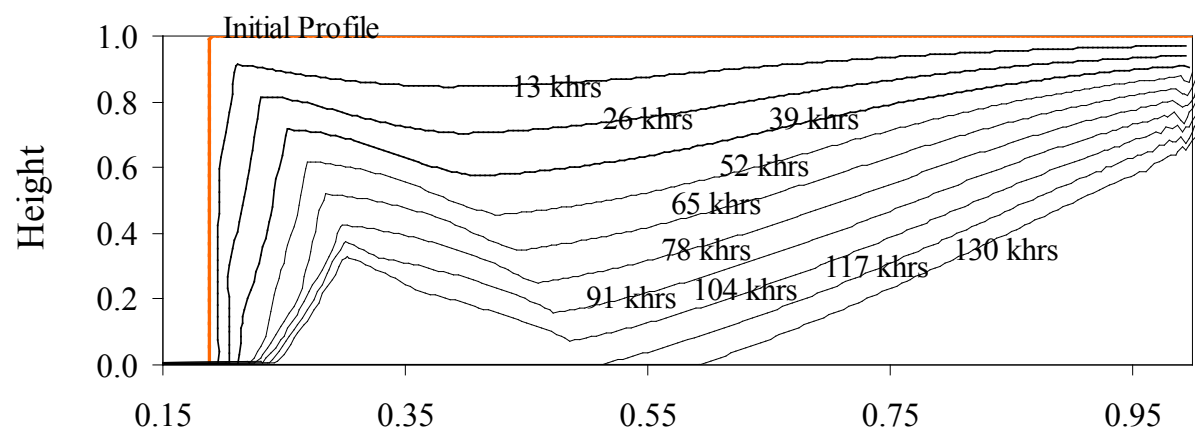

Radial Position

Figure 8.-Graphite discharge cathode wear rate prediction assuming same angular relation as molybdenum at $3.52 \mathrm{~A}$ beam current and $1800 \mathrm{~V}$ beam voltage.

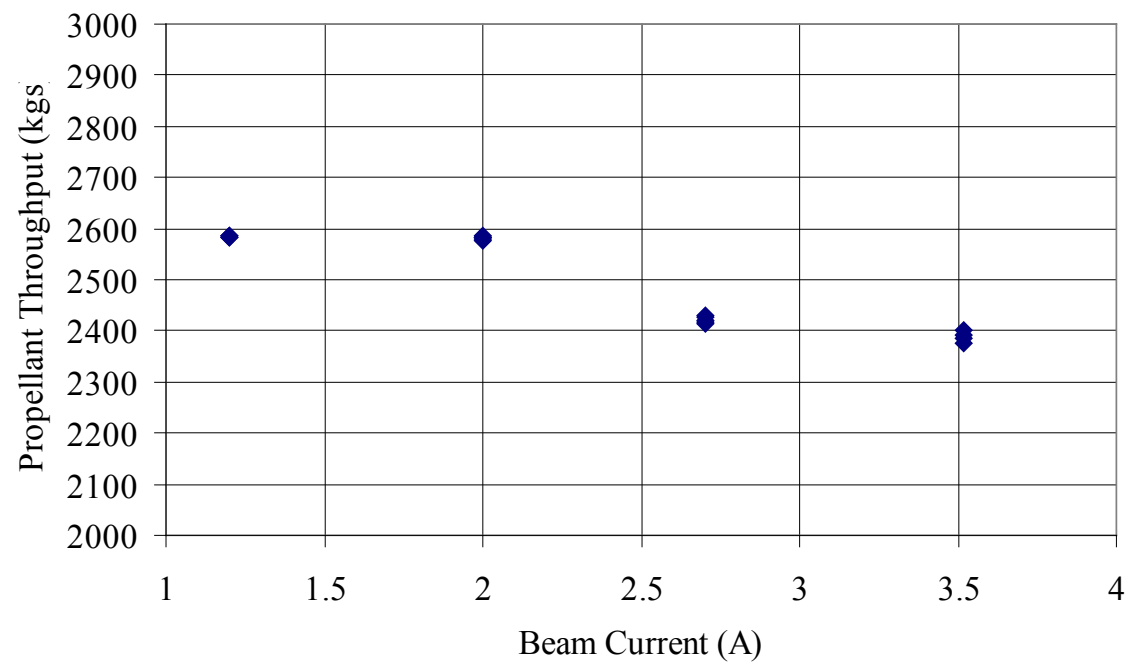

Figure 9.-Graph showing the minimum thruster throughput eroding the NEXT keeper exposing the heater.

A prediction of the relative keeper wear between throttle points can be determined based on ion keeper current and discharge voltage measurements. The propellant throughput calculated here before the cathode heater would be exposed at alternate throttle points was based on the initial prediction of the throughput at the peak power. This initial prediction was scaled for other throttle points based on the ratio of ion keeper current, sputter yield, and discharge flow rate at the two throttle points. The ion keeper current was measured for the NEXT thruster over its throttling range and was found to be a strong function of the beam current (Ref. 31). The change in keeper lifetime from the discharge voltage was included based on the yield data for $\mathrm{C}_{2}$ (the sputter yield of the $\mathrm{C}_{2}$ molecule is greater than the single atom at lower energies) (Ref. 29). The results of using these ratios for various throttle points are shown in Figure 9. The spread at each beam current is due to the variation in discharge voltage. It can be seen that the observed change in discharge voltage would appear to be an insignificant effect on its lifetime. The propellant throughput when the keeper would sufficiently erode to expose the heater increases slightly as the beam current decreases. Since the throughput on all throttle points predicted is at least 5 times the qualification requirement, the analysis and testing from the LDT indicates that risk of failure due to keeper wear is effectively mitigated.

\section{Cathode Orifice Plate Wear/Keeper Shorting}

The cathode orifice plate experienced very little wear during the NEXT $2000 \mathrm{hr}$ test (Ref. 35). It experienced a slight decrease in diameter from sputter material deposition, but the measured decrease was 
approximately equal to its uncertainty (Ref. 36). As long as the orifice plate is protected by the keeper, minimal wear is anticipated. The cathode orifice diameter decreased slightly from deposited materials, but is not expected to change much over the life of the thruster. The orifice diameter in the NSTAR ELT essentially remained constant over the $30 \mathrm{khr}$ of operation (Ref. 5). As of $207 \mathrm{~kg}$ xenon throughput and $10,100 \mathrm{hr}$ of operation during the NEXT LDT, the orifice and the cathode orifice plate have shown no measurable wear (Ref. 15). This indicates that the cathode orifice plate is sufficiently protected by the graphite keeper for at least $2000 \mathrm{~kg}$ of thruster propellant throughput and should have a lifetime many times the qualification requirement.

During the NEXT $2000 \mathrm{hr}$ wear test, material was deposited on the upstream surface of the keeper (Ref. 35). This also occurred during NSTAR wear testing (Ref. 6). If the material was assumed to be deposited at a linear rate, the gap of the NEXT discharge cathode would be bridged after $560 \mathrm{~kg}$ of thruster throughput. This would likely lead to an electrical short between the cathode and the keeper and, therefore, increased keeper wear, but well beyond the qualification requirement of $450 \mathrm{~kg}$ throughput. An electrical short is not expected to compromise the ignition or operation of the thruster as confirmed from the NSTAR ELT (Ref. 33).

\section{NEXT Neutralizer Cathode Lifetime}

The neutralizer on the NEXT thruster is a hollow cathode very similar to the discharge cathode, albeit $1 / 2$ the diameter. The purpose of the neutralizer is to produce the electrons necessary to neutralize the ion beam, thereby, keeping the spacecraft from charging. The primary lifetime constraints on the neutralizer cathode are the depletion of low work function material from the impregnated insert, which would lead to increase temperatures and difficulty in ignition, the neutralizer keeper wear, neutralizer orifice clogging (Ref. 5), and failure of the heater's center insulator from cyclic operation.

\section{Insert Barium Depletion}

The same model used for the discharge cathode can be implemented for the neutralizer cathode. The corresponding temperatures used were based on insert temperature measurements from a similarly sized cathode (Ref. 26). The temperature data was extrapolated using the thermal model described in Reference 37 for operation below 6 A since this was below the lowest current level reported with temperature data. Using the NEXT throttle table as shown in Table 1, a propellant throughput capability based on beam current can be established. This throughput projection is shown in Figure 10 using tighter temperature margins than the discharge cathode since direct insert temperature measurements are used

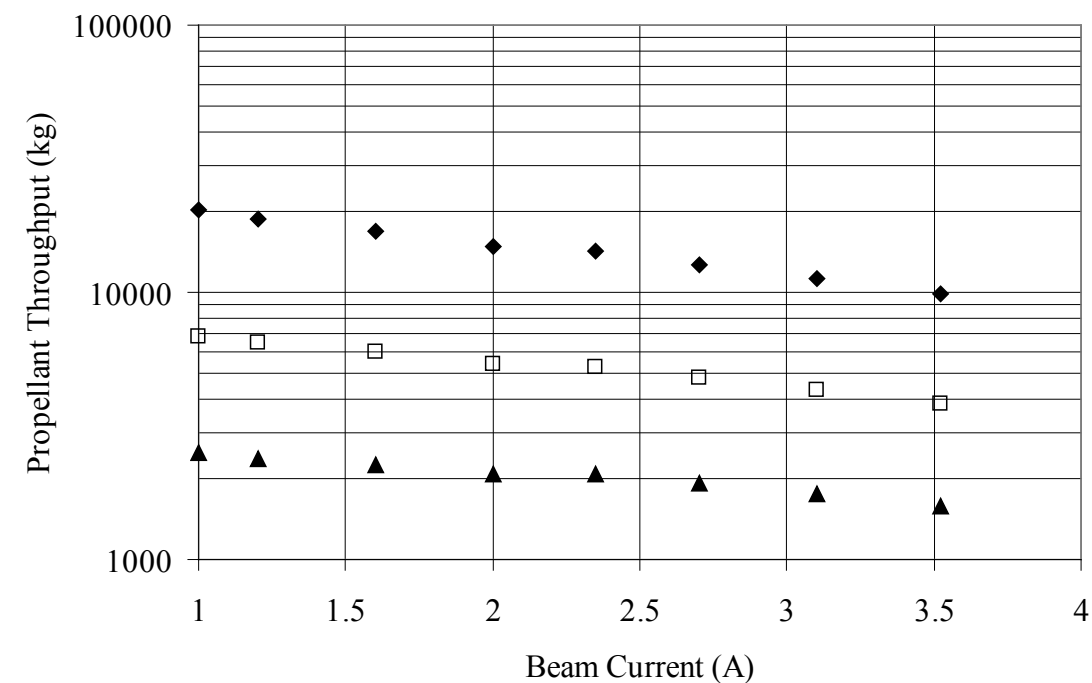

- Peak Insert Temp. $=$ Measured Insert Temp. $-50{ }^{\circ} \mathrm{C}$

$\square$ Peak Insert Temp. $=$ Measured Insert Temp.

$\Delta$ Peak Insert Temp. $=$ Measured Insert Temp. $+50{ }^{\circ} \mathrm{C}$

Figure 10.-NEXT Neutralizer insert lifetime as a function of thruster beam current for insert temperatures $\pm 50{ }^{\circ} \mathrm{C}$ of measurements for a comparably sized cathode. 
instead of orifice plate temperatures. The neutralizer insert is anticipated to exceed the discharge insert lifetime, since it operates at a cooler temperature, and operate with a thruster xenon throughput in excess of $1000 \mathrm{~kg}$. For further comparison, the neutralizer cathode has similar geometry to the cathode that was wear tested for $28 \mathrm{khr}$ at $12 \mathrm{~A}$ (Ref. 25). So, a realistic expectation would be for the NEXT neutralizer insert to operate cooler than the 12 A case and provide well in excess of the $28 \mathrm{khr}$ demonstrated by that cathode.

\section{Neutralizer Keeper Wear}

The wear on the neutralizer keeper face has generally not been a failure mechanism. The NSTAR ELT test actually experienced net deposition on the keeper face (Ref. 5). There was no wear measured on the NEXT neutralizer keeper face after the $2000 \mathrm{hr}$ wear test and it is not considered to impact the life of the thruster (Refs. 35 and 36).

However, the most susceptible part of the neutralizer keeper is the portion of the tube facing the thruster beam. The NSTAR neutralizer tube wall was measured to have eroded up to 20 percent of its thickness during the $30,352 \mathrm{hr}$ of operation during the ELT (Ref. 5). The neutralizer keeper wall facing the beam in the NEXT $2000 \mathrm{hr}$ test experienced wear up to 7.5 percent through its radial thickness (Refs. 35 and 36). This would indicate that the neutralizer keeper could wear to the point where a small hole could form after $27 \mathrm{khr}$, which is approximately $570 \mathrm{~kg}$ of xenon throughput. However, this hole would still not constitute a failure. Any heater or cathode tube wear that would subsequently occur could lead to a failure. An analysis of neutralizer wear from direct impingement of beam ions and elastically scattered beam ions from the background neutrals was also performed (Ref. 38). In that analysis, the axisymmetric code PlumeTool was used to evaluate the thruster plume along with $C E X 2 D$. That analysis found that the major component of the erosion on the side of the neutralizer was from direct impingement by plume ions. It was also determined that since the PM ion optics have a reduced beam diameter of 36 $\mathrm{cm}$ when compared to the EM ion optics used in the $2000 \mathrm{hr}$ test, the direct impingement of the beam on the neutralizer would be removed and wear on the PM neutralizer keeper side should be negligibly small.

In addition, the neutralizer keeper tube wall thickness was increased by 50 percent following the NEXT $2000 \mathrm{hr}$ test. So if the wear is conservatively assumed to be comparable to the $2000 \mathrm{hr}$ test and considered linear, it would now take approximately $850 \mathrm{~kg}$ of xenon throughput before a hole would form.

\section{Neutralizer Orifice Clogging and Orifice Plate Wear}

One of the issues experience during the NSTAR ELT test was the formation of debris in the neutralizer orifice that led to higher keeper voltages and decreased flow rate margins to plume mode (Refs. 5 and 33). The clogging of the neutralizer cathode orifice is difficult to assess since it occurred during testing, but at the end of the test no clogging material remained for analysis. The neutralizer orifice in the NSTAR ELT appeared to be about 50 percent blocked during a portion of the test when it was operating at its lowest throttle point (Ref. 5). While it is unknown what partially blocked the orifice, the material was removed when the engine was throttled back up to full power and the neutralizer keeper voltage and flow rate margin to plume mode returned to values corresponding to nominal operation. During the post test analyses, no evidence of deposits could be found.

Without knowledge of what the material was in the orifice or how it occurred during the NSTAR ELT, it is not possible to predict whether this would occur on the NEXT neutralizer cathode. However, the neutralizer orifice in the NEXT $2000 \mathrm{hr}$ test decreased by approximately 1.1 percent from net deposition from facility sputtering and cathode orifice plate material (Ref. 17). To date, no neutralizer orifice clogging has been witnessed during the NEXT LDT (Ref. 15). The NEXT neutralizer orifice diameter is almost twice as large as the NSTAR neutralizer orifice and higher emission currents are experienced. Both of these factors should minimize the likelihood of neutralizer clogging. It is expected that clogging will not occur prior to any other neutralizer event such as a possible keeper hole forming at $850 \mathrm{~kg}$ of propellant throughput. 
The neutralizer orifice plate in the NEXT $2000 \mathrm{hr}$ test experienced no measurable wear through its thickness (Ref. 17). This is consistent with the lack of erosion found on the NSTAR neutralizer orifice plate thickness during the ELT (Ref. 5). The final orifice wear from the ELT appeared to have the same profile and magnitude of a previous thruster tested to $8200 \mathrm{hr}$. This would indicate that the orifice wear occurs until the orifice reaches a steady state configuration and then the wear ceases to continue. The minimum orifice diameter of the NEXT neutralizer in the LDT has not changed. Based on the testing to date, neutralizer orifice plate wear is not expected to impact the life of the NEXT thruster.

\section{Swaged Heater Cyclic Life}

The swaged heaters on the discharge and neutralizer cathodes are used during the ignition process to raise the temperature of the impregnated insert to facilitate initial electron emission. Once the cathodes are ignited, the heaters are turned off and the cathodes self-heat from the generated plasma. This on-off cycling of the heater could lead to mechanical failure of the heater center conductor and requires that the heaters be validated for sufficient cyclic lifetime operation. Previously, cyclic life testing was performed on the neutralizer heater design for the International Space Station (ISS) Plasma Contactor hollow cathode assembly (Refs. 39 and 40). These heaters were validated to have a $\mathrm{B}_{10}$ life of approximately 6700 cycles (this corresponds to the cycles at which 10 percent of the population of heaters would fail). The NSTAR heaters were the same design and from the same manufacturer as the tested hollow cathode assembly heaters, so cyclic testing was not needed to demonstrate that they met the NSTAR requirements. However, the NEXT discharge heater design is slightly different than the tested hollow cathode assembly heater and from a different manufacturer, so the plan is to also validate the PM heater cyclic lifetimes through similar testing (Ref. 41).

\section{Accelerator Grid}

Two grids are employed to extract the ions generated in the discharge chamber of the ion thruster. The inner or screen grid is at a potential similar to the discharge chamber and protects the accelerator grid, which is at a significantly lower potential, by focusing the ions through the accelerator grid holes. The accelerator grid has a negative potential with respect to the spacecraft environment to prevent neutralizer electrons from backstreaming into the discharge chamber.

There are two main accelerator grid specific failure modes related to wear mechanisms. The first is structural failure due to "pit and groove" erosion between the apertures on the downstream side of the accelerator grid. This erosion is caused by charge exchange ions produced just downstream of the accelerator grid. These ions are focused into the region between two holes to form grooves, as shown in Figure 11, and into the region equidistant to three adjacent holes to form pits. For this study, the accelerator grid is assumed to structurally fail when the groove penetrates through the accelerator grid resulting in the end-of-life of the thruster. This wear is related to a number of factors including the beam current density, neutral density, and accelerator voltage. The greatest amount of wear from pit and groove erosion is typically at the center of the grid where the beam density is the highest.

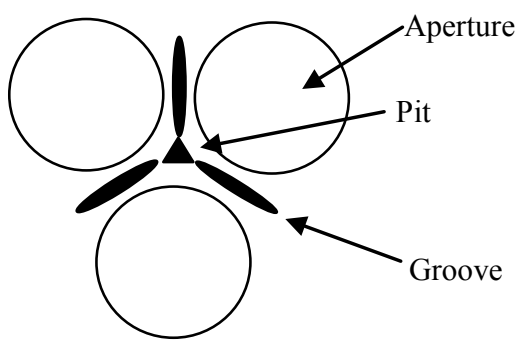

Figure 11.-Pit and groove erosion on the accelerator grid. 
The second failure mode is electron backstreaming resulting from aperture barrel erosion. This erosion takes place on the inside wall of the aperture from charge exchange ions produced in the region between the grids. As the apertures increase in diameter from erosion, the magnitude of the potential at the center of the hole will eventually drop and fail to repel the electrons from the neutralized beam. This results in electrons backstreaming into the discharge chamber with high energy and quickly damaging components such as the discharge cathode. However, if it is determined that backstreaming will occur after a certain throughput, the accelerator power supply can be adjusted to prevent backstreaming and mitigate this issue with only a minor impact on the lifetime due to structural failure.

In this study, the NEXT propellant throughput capability corresponding to the accelerator grid structural failure will be determined at full power by extrapolating the results from the NEXT $2000 \mathrm{hr}$ wear test and the LDT and then comparing these results to predictions from optics modeling. Then, based on the predicted propellant throughput capability at full power, the throughput capability at other throttle points will be determined based on the relative change of the dominant wear mechanisms. This throughput prediction across the throttle table will then be used to predict the amount of groove erosion expected based on three different mission profiles.

\section{Structural Failure from Downstream Erosion}

\section{$2000 \mathrm{hr}$ Wear Test and NEXT LDT Results}

The nominal NEXT optics design geometry is the same as the nominal NSTAR optics geometry with the exception that the NEXT optics has 1.6 times the beam area and an accelerator grid that is 1.5 times thicker than the NSTAR accelerator grid (Refs. 42 and 43). The service life of the NEXT accelerator grid is increased by the addition of material to its thickness. If the wear rate in the pits of the NEXT grids during the $2000 \mathrm{hr}$ test is assumed linear, the pits would wear through the grid's thickness after $17.5 \mathrm{khr}$, or $365 \mathrm{~kg}$ of xenon, which is $85 \mathrm{~kg}$ less than the $450 \mathrm{~kg}$ throughput qualification requirement (Ref. 17). However, as previously mentioned, it is the grooves that would constitute a structural failure. A linear extrapolation from the NEXT wear test would indicate that the deepest point of the grooves would wear through after $35.5 \mathrm{khr}$ or $\sim 750 \mathrm{~kg}$ of xenon, which is 1.7 times the qualification requirement (Ref. 17). Based on the latest in situ measurements during the NEXT LDT, the groove is predicted to penetrate the grid's thickness between 700 to $800 \mathrm{~kg}$ of propellant throughput at the peak operating power (Ref. 15).

\section{Previous Computer Models}

Several different computer software models, such as CEX3D (Ref. 44), CEX2D (Ref. 44), ffx (Ref. 11), erode (Ref. 10), and MICHELLE (Ref. 45), have been used to examine NEXT accelerator grid erosion. Table 3 shows the pit and groove penetration of the NEXT accelerator grid based on predictions from the codes and an extrapolation of the NEXT LDT and $2000 \mathrm{hr}$ wear test results. The models predict a groove penetration of $590 \mathrm{~kg}$ and $770 \mathrm{~kg}$ of xenon at the peak throttling point, which is 140 to $320 \mathrm{~kg}$ more than qualification requirement. However, the CEX3D code is known to over-predict groove wear by 2 times the observed rates (Ref. 44). Taking that into account would yield an expected throughput of greater than $1000 \mathrm{~kg}$ for groove penetration. It should also be pointed out that some of the largest areas of uncertainty with the optics models pertain to grid gap, beamlet currents and redeposition of sputtered material into the pits or grooves. Recently, testing has shown the NSTAR operational or "hot" grid gap to be less than most previously assumed (Ref. 46). Incorrect assumptions can easily cause the predictions of the codes to vary by tens of percent when predicting wear. This highlights the importance of wear data to calibrate the models and further thruster testing with diagnostics to reduce the uncertainties of model inputs. Based on a combination of testing and computer modeling, the accelerator grid is anticipated to reach end of life at $750 \mathrm{~kg}$. 
TABLE 3.-PROPELLANT THROUGHPUT PREDICTIONS OF PIT AND

\begin{tabular}{|l|c|c|c|c|}
\multicolumn{1}{c|}{ GROOVE PENETRATION AT FULL POWER ON THE NEXT ACCELERATOR GRID } \\
\cline { 2 - 5 } & CEX3D & $\mathrm{ffx}$ & $\begin{array}{c}\text { NEXT 2000 hr } \\
\text { test }\end{array}$ & NEXT LDT \\
\hline Pit penetration $(\mathrm{kg})$ & 245 & 610 & 365 & ------- \\
\hline Groove penetration $(\mathrm{kg})$ & 590 & 770 & 750 & $700-800$ \\
\hline
\end{tabular}

\section{Extrapolation of Wear Test and Analytical Results Over the NEXT Throttle Table}

Based on the NEXT $2000 \mathrm{hr}$ wear test, the NEXT LDT, and with the computer models presented here, the propellant throughput coinciding with groove penetration at a beam current of $3.52 \mathrm{~A}$ and beam voltage of $1800 \mathrm{~V}$ would occur approximately at $750 \mathrm{~kg}$. It is possible to use the relative change in dominant factors affecting the pit and groove wear rate to predict throughputs at a variety of throttling points on the NEXT throttle table. These dominant factors are the production of charge exchange ions and the sputter yield based on ion energy. A first order approximation of the wear rate can be approximated by Equation (1), where $C$ is a constant assuming that the wear rate is proportional to the production of charge exchange ions and $Y$ is the sputter yield of the grid material.

$$
\text { Wear Rate }=C \cdot I_{c x} \cdot Y
$$

The charge exchange ion production, $I_{c x}$, can be calculated with Equation (2) where $n_{o}$ is the neutral density, $n_{+}$is the ion density, $\mathrm{Vol}$ is the volume of the charge exchange production region, $\sigma_{c x}$ is the ion charge exchange cross section, and $v_{i}$ is the ion velocity.

$$
I_{c x}=n_{o} \cdot n_{+} \cdot e \cdot \mathrm{Vol} \cdot \sigma_{c x} \cdot v_{i}
$$

The neutral density immediately upstream of the grids can be approximated by using the mass flow into the discharge chamber, $\dot{m}_{d c i n}$, the beam current, $I_{B}$, the double to single ion ratio, $I^{I^{+}} / I^{+}$, and the neutral

velocity, $v_{o}$, leaving through the optics as shown in Equation ( ).

$$
n_{o}=\left[\dot{m}_{d c \text { in }}-\left(I_{B} \cdot \frac{1+I^{++} / I^{+}}{1+2 \cdot I^{++} / I^{+}}\right) \text {mass equiv. }\right] / v_{o}
$$

The ion density can be calculated using the peak beam current density, $j_{b, p e a k}$, divided by the ion velocity.

$$
n_{+}=j_{b, \text { peak }} / v_{i}
$$

The volume of the charge exchange production region can be estimated by assuming a constant beamlet cross section, $A_{B}$, multiplied by the neutralization length, $l_{n}$, and shown in Equation (5) (Ref. 47). $\beta$ is a constant based on the ion mass, $V_{N E T}$ is the beam supply voltage plus the coupling voltage, which is measured between the neutralizer common to tank ground, and $\mathrm{R}$ is the R-ratio for an ion thruster, which is $V_{N E T}$ divided by $V_{b p s}$ plus the absolute value of the accelerator voltage.

$$
V o l=A_{B} \cdot l_{n}=A_{B} \cdot\left[\frac{\beta \cdot V_{N E T}^{1.5} \cdot\left(R^{-1.5}+3 R^{-1}-4\right)}{j_{b, \text { peak }}}\right]^{0.5}
$$


Assuming linear wear, the lifetime of the grids can then be simply computed by dividing the thickness of the grid by its wear rate. The corresponding propellant throughput of the thruster can then be calculated by Equation (6).

$$
\text { Throughput }=(\text { Grid Thickness } / \text { Wear Rate }) \cdot \dot{m}
$$

To determine the relative change in propellant throughput, Equations (1) to (6) can be combined with the assumption that $C, \beta$, the neutral velocity and beamlet cross sectional area are constant to give:

$$
\begin{aligned}
& \frac{(\text { Throughput })_{2}}{(\text { Throughput })_{1}}= \\
& =\frac{\left(\left(\dot{m}_{d c \text { in }}-\left(I_{B} \cdot \frac{1+I^{++} / I^{+}}{1+2 \cdot I^{++} / I^{+}}\right)_{\text {mass equiv. }}\right) \cdot V_{N E T}^{1.5} \cdot\left(R^{-1.5}+3 R^{-1}-4\right) \cdot j_{b, \text { peak }}^{0.5} \cdot \sigma_{c x}\right)_{1}}{\left(\left(\dot{m}_{d c \text { in }}-\left(I_{B} \cdot \frac{1+I^{++} / I^{+}}{1+2 \cdot I^{++} / I^{+}}\right) \cdot V_{N E T}^{1.5} \cdot\left(R^{-1.5}+3 R^{-1}-4\right) \cdot j_{b, \text { peak }}^{0.5} \cdot \sigma_{c x}\right)_{2}\right.} \\
& \cdot \frac{(Y)_{1}}{(Y)_{2}} \cdot \frac{(\dot{m})_{2}}{(\dot{m})_{1}}
\end{aligned}
$$

The charge exchange cross section is determined based on the ion energy, which is a function of the beam and accelerator voltage on an ion thruster. The relation used is reported in Reference 48. It is assumed that the sputter yield is determined primarily by the accelerator voltage and the relationship used is reported in References 29 and 49.

Using Equation (7), along with test and analysis results for the $3.52 \mathrm{~A}, 1800 \mathrm{~V}$ operating condition, propellant throughputs at other throttle points can be predicted for structural failure of the accelerator grid. These predicted throughputs and lifetimes for various specific impulses on the throttle table are shown in Figure 12. Figure 13 depicts these same throughputs and lifetimes as a function of thrust. All of the operating conditions are predicted to have throughputs exceeding the maximum power throttling point and qualification requirement except at the three lowest specific impulses and thrusts. The lowest two throttle points are the only ones predicted to have less than the $450 \mathrm{~kg}$ propellant throughput requirement with 410 and $320 \mathrm{~kg}$ throughput predicted. This method of predicting lifetime and propellant throughput agrees well with the ffx predictions at various throttling points. The propellant throughput prediction that varies the most between the two methods is at the lowest power. The ffx model predicts groove penetration at significantly higher throughput of $1040 \mathrm{~kg}$. However, the ffx model does show much larger area pits than at the higher power throttle points and these pits penetrate at $280 \mathrm{~kg}$ of throughput. This would seem to indicate that the 300 to $400 \mathrm{~kg}$ propellant throughput predictions for structural failure are conservative predictions.

While propellant throughput capability at the lowest two throttle points is below the $450 \mathrm{~kg}$ qualification requirement, the driving requirement is really based on a particular mission profile. Of the different mission scenarios examined, there were three missions that had operation at the lower three power throttling points (Ref. 4). These included a rendezvous mission to Vesta-Ceres, a comet sample return mission, and a Titan direct lander mission. Figure 14 through Figure 16 show the time spent and predicted accelerator groove wear at specific throttle points for these missions. In these figures, the time spent at a throttle point represents the total accumulated time among all thrusters and the predicted groove wear is based on an individual thruster assuming that the duration is equally divided over the number of thrusters used. The mission assumption for Vesta-Ceres is that two thrusters are used in sequential order 
with the first thruster operating primarily at the high power throttle points to deliver the spacecraft to the asteroid Vesta, with the second thruster then used for much of the lower power throttling to Ceres. For simplicity, this analysis assumed equal distribution between the two engines. However, if the duration at $37 \mathrm{mN}$, which has an individual propellant throughput of $600 \mathrm{~kg}$, is assumed to be on a single engine the erosion through the accelerator grid would be at most 4 percent of its thickness. Operation at that lowest throttle point clearly is not a significant driver for that mission.

The mission that had the longest operation at the lowest specific impulses was the comet sample return mission. It was assumed that two thrusters were used on that mission. When its entire mission throttle histogram is used to predict grid life, accelerator grid groove erosion will be through 33 percent of the grid thickness with less than a quarter of that erosion from operation at or below a thrust of $37 \mathrm{mN}$.

The Titan direct lander mission assumes one thruster. On that mission, groove erosion from operation at or below $37 \mathrm{mN}$ accounts for only 4 percent out of the 26 percent erosion through the grid.

It can be seen that the missions examined using the lower throttle points that violate the $450 \mathrm{~kg}$ propellant throughput requirement would still yield an accelerator grid structural failure propellant throughput that was at least two times the mission throughput required. An additional consideration is a recent recommendation that the accelerator voltage be operated with reduced margin at these lower thrusts and specific impulses because of the improved perveance margins offered by the PM ion optics (Ref. 50). The resulting effect on lifetime and throughput at those throttle points is shown in Figure 12 and Figure 13 with open symbols and would result in all of the propellant throughput capabilities exceeding the $450 \mathrm{~kg}$ throughput requirement.

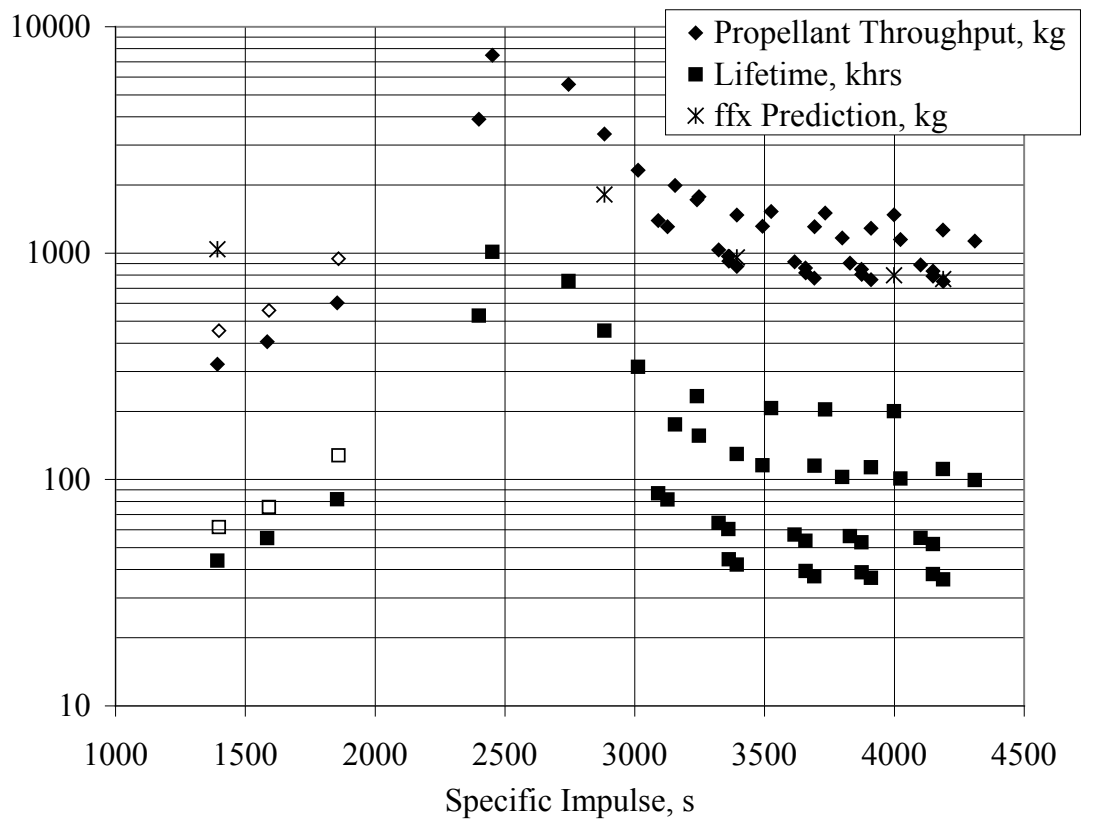

Figure 12.-The throughput and lifetime predicted before structural failure of the accelerator grid due to groove penetration for specific impulses at various throttling points. The open symbols represent the values based on a suggested modification to the throttle table (Ref. 50). 


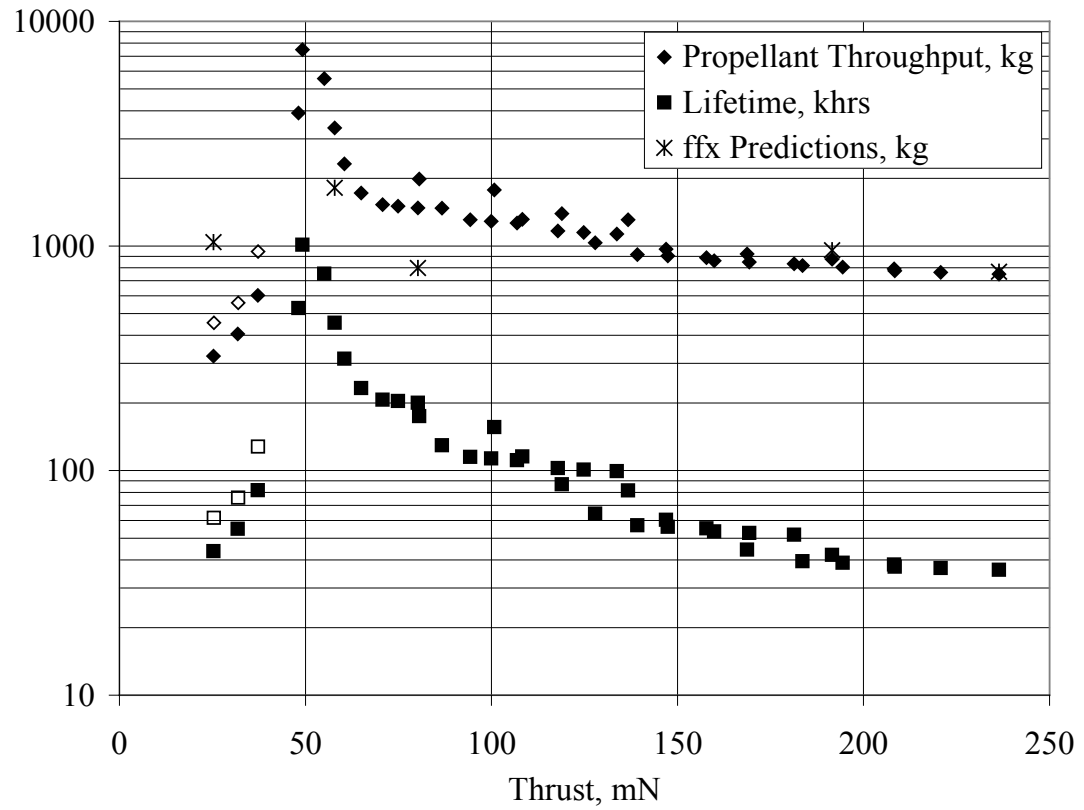

Figure 13.- The throughput and lifetime predicted before structural failure of the accelerator grid due to groove penetration as a function of thrust at various throttling points. The open symbols represent the values based on a suggested modification to the throttle table (Ref. 50).

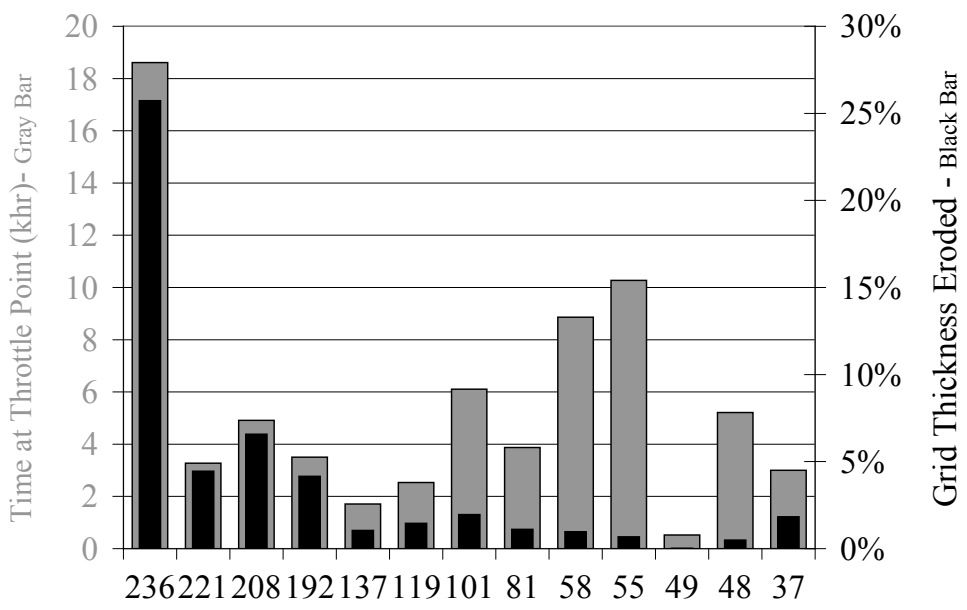

Thrust $(\mathrm{mN})$

Figure 14.-Relative groove wear through accelerator grid and time at throttle point for Vesta-Ceres mission. Wear at groove from the total mission is predicted to be 51 percent of the grid thickness. 


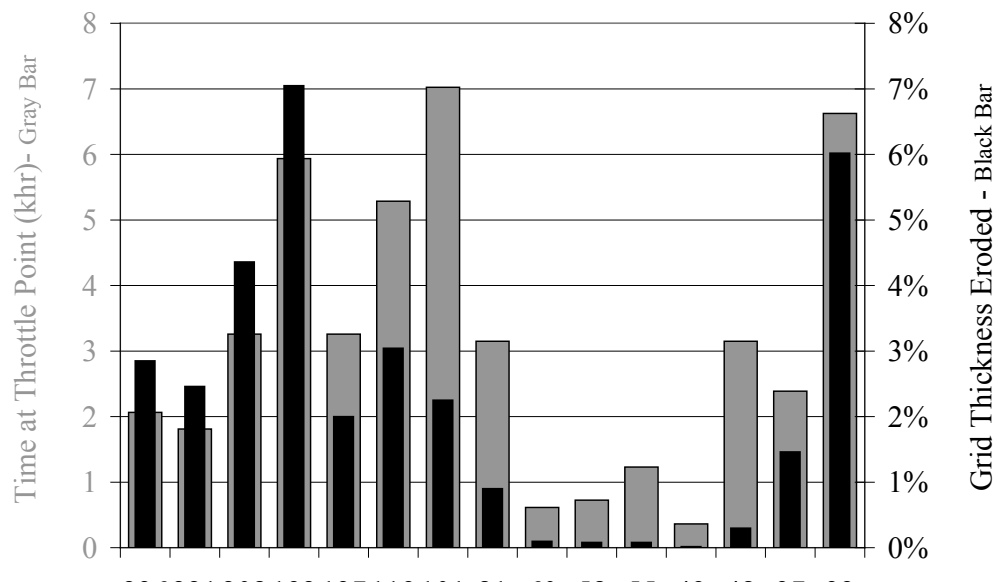
$23622120819213711910181 \quad 60 \quad 58 \quad 55 \quad 49 \quad 48 \quad 37 \quad 32$

Thrust $(\mathrm{mN})$

Figure 15.- Relative groove wear through accelerator grid and time at throttle point for comet surface sample return mission. Wear at groove from the total mission is predicted to be 33 percent of the grid thickness.

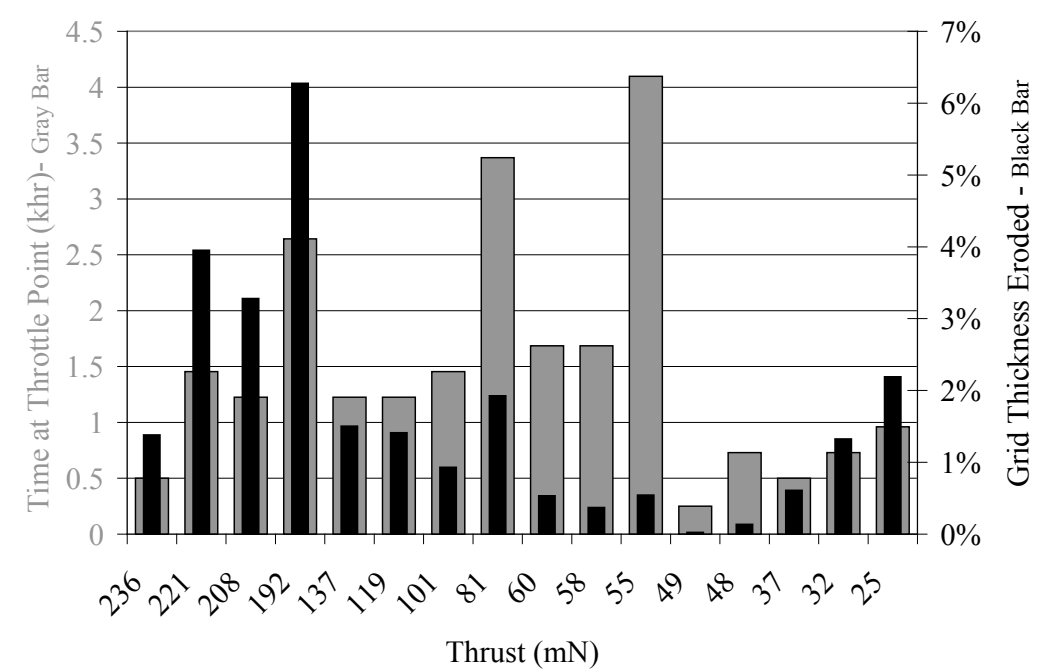

Figure 16.- Relative groove wear through accelerator grid and time at throttle point for Titan direct lander mission. Wear at groove from the total mission is predicted to be 26 percent of the grid thickness.

\section{Barrel Erosion Resulting in Electron Backstreaming}

Modeling of the accelerator aperture barrel erosion and resulting electron backstreaming appears even more difficult for the ion optics codes. While some have predicted the initial electron backstreaming limit reasonably well, they do not agree with the results from wear testing the NEXT thruster for how that limit changes with extended operation. The models have generally predicted that after $45 \mathrm{~kg}$ of throughput at full power, the backstreaming limit would have decreased by $10 \mathrm{~V}$ and after $200 \mathrm{~kg}$ of propellant throughput the backstreaming limit would have decreased by $20 \mathrm{~V}$ due to aperture barrel erosion. Both the NEXT $2000 \mathrm{hr}$ test after $43 \mathrm{~kg}$ of propellant throughput and the NEXT LDT after $207 \mathrm{~kg}$ of xenon throughput and 10,100 hr of operation have shown no significant change in the electron backstreaming limit (Refs. 15 and 17). Due to the inability of the codes to accurately predict the change in electron backstreaming limit, the best indicators are the current wear tests. These tests indicate that failure from backstreaming electrons due to barrel erosion will not occur prior to any structural failure of the 
accelerator grid at the peak power throttle point. However, since the models do not accurately predict the trend in the electron backstreaming limit, further work is needed for evaluation of throughput capability at other throttle points.

\section{Screen Grid Erosion}

The failure possible with the screen grid would be excessive erosion from the discharge plasma leading to structural failure of that grid. Early ion thrusters exhibited higher rates of erosion on the screen grids (Ref. 7), but subsequent operational changes to the NSTAR thruster related to the screen grid potential and discharge voltage have significantly reduced the wear of the screen grid. The NSTAR screen grid apertures only exhibited slight chamfering on the upstream side during the $8200 \mathrm{hr}$ test (Ref. 6) and less than $60 \mu \mathrm{m}$ of chamfering during the NSTAR ELT (Ref. 51). It is possible to correlate the net erosion of the screen grids between the NSTAR thruster and the NEXT thruster. The net erosion on the screen grid per mass of propellant throughput, shown in Equation (8), is dependent on the sputter yield, $Y$, screen grid ion transparency, $\phi_{s g}$, beam current, $I_{B}$, and the propellant flow rate, $\dot{m}$.

$$
\gamma / \dot{m}=Y \cdot\left(1-\phi_{s g}\right) \cdot I_{B} / \dot{m}, \quad(\text { sputtered atoms } / \text { propellant throughput })
$$

The NEXT thruster and NSTAR thruster both operate with discharge voltages between 23 to $28 \mathrm{~V}$, which would yield ions with similar energies, and sputtering yields, impacting the screen grid (Refs. 15 and 33) The screen grid ion transparency on the NSTAR optics is between 0.80 to 0.88 and on the NEXT optics is 0.78 to 0.90 (Refs. 6,15 , and 33). The beam current per total propellant mass flow rate is 1.68 to $2.10 \mathrm{~A} / \mathrm{mg} / \mathrm{s}$ on the NSTAR thruster and is 1.58 to $1.85 \mathrm{~A} / \mathrm{mg} / \mathrm{s}$ on the NEXT thruster. If these values are used in Equation (8), the NSTAR thruster bulk screen grid erosion per mass of propellant throughput would be 6 to 14 percent higher than the NEXT thruster. This result, along with the lower doubly charged ion content and lower peak beam current density of the NEXT thruster, would indicate that the NEXT screen grid wear rate is anticipated to be less than that for NSTAR. The screen grid in the NEXT $2000 \mathrm{hr}$ test exhibited no signs of excessive erosion (Ref. 17). Screen grid erosion on the NEXT engine is at such a slow rate that is considered insignificant. The propellant throughput capability based on screen grid erosion will be well in excess of the first anticipated failure mode at $750 \mathrm{~kg}$ of propellant throughput.

\section{Optics Assembly Electrical Shorting}

A primary failure mechanism that could be caused by the discharge chamber is the grid shorting. This could be caused by debris or sputtered material bridging the gap between the grids. Brief electrical shorting of the grids will not result in failure, but failure would result from an unclearable electrical short. It is important to take a fourfold approach to prevent failure from electrical shorting. This approach would be to minimize sputtering, retain as much sputtered material on the discharge chamber walls as possible, prevent any sputtered material that isn't retained be to be of a size such that it cannot bridge the optics gap, and provide a process to clear any material that does create an electrical short.

\section{Minimize Sputtering}

The cathode keeper and the ion optics are the two primary contributors to sputtered material. As previously mentioned, the cathode keeper material was changed to graphite to reduce the wear rate, and hence, the rate at which it sputters material into the discharge chamber. Upstream screen grid aperture erosion is also a source of sputtered material. However as was discussed previously, screen grid operational changes have greatly reduced the amount of sputtering that occurs here. Erosion of the accelerator grid in the aperture also produces sputtered material that would be deposited on either of the grids or the discharge chamber. This would come from either an under-focused or over-focused beamlet resulting in either uniform barrel or hexagonally shaped cross-over erosion, respectively. Under-focused 
beamlet ions typically occur at the highest beam current densities, which is also typically at the center of the optics. Operation with under-focused beamlets is usually avoided. Uniform barrel erosion can also occur from charge exchange ions. Risk of an electrical short from the material sputtered as a result of under-focused beamlets or charge exchange ions is minimal.

Cross-over erosion generally occurs in areas of low beam current density and relatively high ion optics total voltages. This would typically occur at the outer apertures. Over-focused beamlet ions in the low density region impinge on the accelerator grid producing off-center, hexagonally shaped erosion patterns. Since this erosion is due to direct impingement, once the grid material is removed where the beam impinges, the erosion stops. Since it stops, this erosion does not jeopardize the structurally integrity of the grid, but the sputtered material could contribute to electrical shorting. One of the locations material sputtered from cross-over erosion is deposited is on the inner diameter of the accelerator aperture experiencing crossover erosion. This deposited material could spall and create an electrical short.

During the NEXT $2000 \mathrm{hr}$ test, which was at full power, the accelerator apertures beyond a radius of $15.3 \mathrm{~cm}$ exhibited a hexagonal star-shaped erosion pattern indicative of cross-over erosion (Ref. 17). This wear pattern can be seen in Figure 17. The wear was found to be the result of over-focused beamlet ions in this low plasma density region impinging upon the accelerator grid and significantly smaller-thannominal accelerator aperture diameters in this region (Ref. 17).

To mitigate this wear and minimize the amount of sputtered material, the PM design of NEXT optics reduced the beam extraction diameter to $36 \mathrm{~cm}$. The area outside of $36 \mathrm{~cm}$ was the region of low plasma density, so there was a minimal effect on the performance of the engine, while the erosion mechanism was removed. Another improvement on the PM optics has been that aperture diameters were kept to a tighter tolerance throughout the beam extraction area. Crossover erosion is being monitored closely on the NEXT LDT (Refs. 15 and 52). A photograph of the edge holes taken after $1477 \mathrm{hr}$ of operation during the LDT is also shown in Figure 17. There is no longer any apparent star shaped pattern indicative of crossover erosion on accelerator grid. The hexagonally shaped cross-over erosion has been significantly reduced.

The only remaining cross-over erosion experienced at full power on the PM optics was anticipated and is a "notching" on the outermost apertures as seen in Figure 17. This was witnessed after the NEXT $2000 \mathrm{hr}$ test and previous NSTAR tests (Ref. 8). Modeling of this notching phenomenon was undertaken at the NASA Glenn Research Center using an optics modeling program, which is capable of modeling asymmetric geometries (Refs. 45 and 53). This modeling was able to demonstrate that this erosion is a result of extracting ions from the region where there are no apertures, while hex-shaped outer edge erosion is due to crossover erosion from to low beamlet current density and relatively high extraction voltage. The modeling also concluded that this erosion stops when sufficient material is eroded and does not impact the extraction or structural lifetime capability of the accelerator grid. This notching erosion contributes minimal sputtered material to risk electrical shorting.

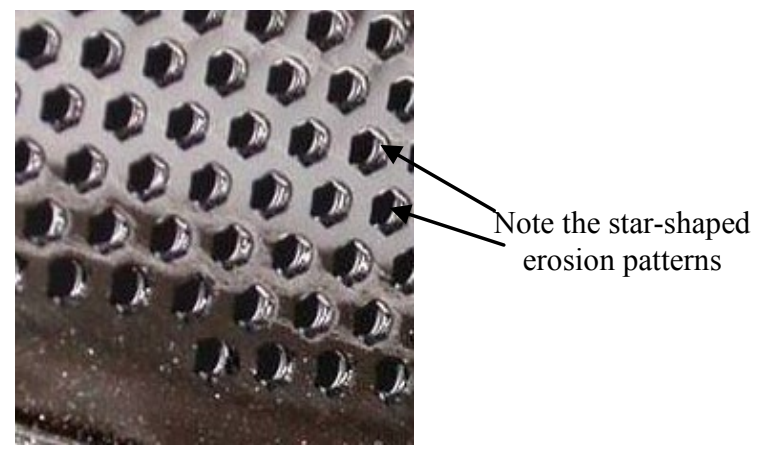

NEXT $2000 \mathrm{hr}$ Test

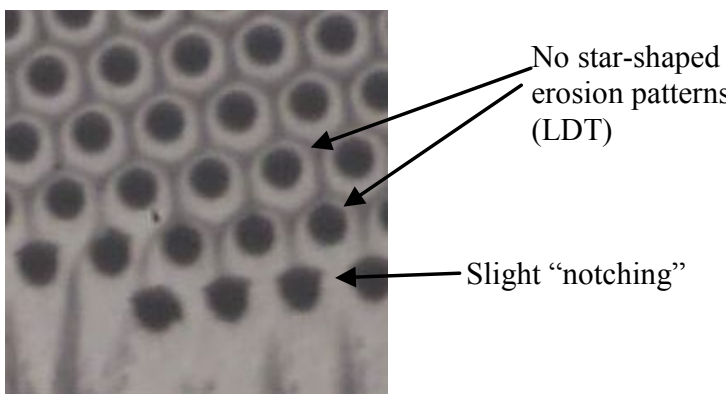

NEXT LDT

Figure 17.-Photographs of the edge holes taken after $2038 \mathrm{hr}$ of operation during the NEXT $2000 \mathrm{hr}$ test and after $1477 \mathrm{hr}$ of operation during the NEXT LDT Test. 


\section{Sputtered Material Retention in Discharge Chamber/Minimize Debris Size}

As previously mentioned, there are two primary contributors to sputtered material on the discharge chamber walls. These are from the cathode keeper and the ion optics, primarily the screen grid. It is predicted that a maximum of $7 \mu \mathrm{m}$ of carbon from the discharge cathode keeper could coat the discharge chamber surface. There has not be a comprehensive study on the adherence of carbon to the wire mesh, but the $2000 \mathrm{hr}$ HiPEP engine, which used a graphite keeper and grit-blasted mesh, showed no evidence of spalling (Ref. 34).

It is anticipated that the largest contributor during flight to material deposition in the discharge chamber will be from the ion optics, primarily the screen grid. As demonstrated in the previous section, the bulk erosion of the NEXT screen grid per propellant throughput would be less than that experienced on the NSTAR thruster. The ratio surface area of the discharge chamber to the screen grid area is roughly 50 percent larger on the NSTAR thruster. These two parameters offset each other when determining a crude prediction of the relative film thickness expected on the discharge chamber walls. So, the NSTAR wear tests provide deposition rates to a first order for the NEXT thruster discharge chamber. Based on the same deposition rates from the NSTAR wear tests, it is predicted that the maximum deposition rate in the discharge chamber would be $7 \mu \mathrm{m}$ per $100 \mathrm{~kg}$ of thruster xenon throughput. Testing has demonstrated that up to $130 \mu \mathrm{m}$ of molybdenum can be sputter deposited onto the grit-blasted wire mesh of the NEXT discharge chamber without spalling off (Ref. 54). This would mean at least $1850 \mathrm{~kg}$ of xenon would need to be processed before reaching $130 \mu \mathrm{m}$ of material deposited on the discharge chamber.

If any material would spall off the discharge chamber walls prior to or after a film thickness of $130 \mu \mathrm{m}$, the wire mesh used on the surface of the discharge chamber is designed to prevent any material spalling of sufficient size to electrically short the optics (Ref. 55). The wire mesh is designed with wire diameters and gaps small enough so that anything spalling should have sizes of that magnitude. This should result in any spalling to be of insufficient size to short between the grids and is a consistent design with the NSTAR and NEXT ion thrusters.

\section{Clearing Debris in Optics}

Even after minimizing the amount of thruster generated material, it is still possible to get a sustained electrical short on the optics. This could be caused by contaminants from spacecraft assembly or launch vehicle debris as well as from the thruster. For example, the NSTAR ion thruster on the Deep Space One mission is thought to have suffered from this type of contamination (Ref. 56). In that mission, the thruster operated at the minimum throttling point for $4.5 \mathrm{~min}$ before the thruster experienced continuous recycling and shut down. Later the thruster ignited properly without continuous recycling and the short appeared to have been cleared by thermal cycling of the thruster.

Since there are various possible sources causing electrical shorting of the grids it is necessary to have a grid debris clearing capability. The NEXT approach to clear the debris is similar to that of the NSTAR thruster of the DS1 spacecraft and is accomplished by connecting the discharge power supply across the screen and accelerator grids to provide the necessary clearing power (Ref. 57). An investigation was undertaken to evaluate the currents and voltages required to vaporize materials commonly produced by an ion thruster (Ref. 58). Alternative methods to clear sample wires from the grids were also investigated, including the use of a capacitor grid clear circuit. It was recommended to initially attempt to clear debris using mechanical means such as thermally cycling the thruster. If that fails, it was determined that the discharge power supply capability is powerful enough to clear the flakes found in the NEXT discharge chamber after the $2000 \mathrm{hr}$ wear test.

It is not possible to provide a propellant throughput prediction related to optics shorting since an electrical short could be caused by spacecraft or launch vehicle debris generated during launch. The risk of failure from an optics electrical short is minimized by reducing debris generation and adopting grid clearing capability and procedures that have been developed on previous ion thruster missions. The NEXT program has done this and should ensure operation well beyond $450 \mathrm{~kg}$ of propellant throughput. 


\section{Discharge Chamber Magnets}

Another issue with previous thrusters was the thermal risk to the permanent magnets. At elevated temperatures permanent magnets can degrade and decrease in magnetic strength resulting in thruster performance degradation. The pre-test and post-test magnetic field mapping of the NEXT discharge chamber for the $2000 \mathrm{hr}$ test showed no such degradation (Ref. 17). There is also no change in discharge performance of the NEXT thruster during the LDT that would indicate a degradation of the magnetic circuit (Ref. 15). Additionally, the NEXT PM thruster operating with the maximum internal heating and under the hottest mission scenario is predicted to have maximum magnet temperatures of 250 to $288^{\circ} \mathrm{C}$, which is slightly cooler than the maximum operational temperatures of $291^{\circ} \mathrm{C}$ on the magnets of the NSTAR ion engine (Refs. 59 and 60). In addition, the NEXT magnets were stabilized to a higher temperature than the magnets used on the NSTAR ion engine. The higher stabilization temperatures and slightly cooler operating temperatures assure that the NEXT magnets will degrade slower than the NSTAR magnets, which have demonstrated $30+\mathrm{khr}$ of operation without degradation (Ref. 5). The magnets on the NEXT thruster should demonstrate adequate magnetic strength beyond the first thruster failure mode at $750 \mathrm{~kg}$ of propellant throughput.

\section{High Voltage Propellant Isolators}

The high voltage propellant isolators (HVPI) are used in the xenon feed lines to the discharge chamber. The risk with HVPI is that at excessive temperature and voltage, a leakage current across the isolator would increase to unacceptable levels with extended use. This increased current may not constitute a thruster failure, but an increase in power loss in the thruster system. The NEXT HVPI design concept is based on the NSTAR HVPI that was successfully tested at the component level and thruster level for 16,000 and 30,000 hr, respectively (Refs. 61 and 33). This HVPI design philosophy employed on the NEXT thruster is also the same as the NSTAR thruster, but procured from a different manufacturer (Refs. 62 and 63). The risk of failure is low if the manufacturing processes and materials similar to those of the NSTAR isolators. Design verification tests are currently being conducted on the NEXT HVPI (Ref. 41). At the date of this writing, the HVPI design verification test has operated for more than $10,300 \mathrm{hr}$ at $260{ }^{\circ} \mathrm{C}, 2300 \mathrm{~V}$, and with an internal pressure of $2.7 \mathrm{kPa}$ and have met the expected performance characteristics. The HVPI's are currently showing a trend of $0.1 \mathrm{nA}$ per $1600 \mathrm{hr}$ (Ref. 41). A leakage current maximum of $100 \mu \mathrm{A}$ is the requirement based on NSTAR thruster (Ref. 41). Based on the current trends of the test, that definition of failure would yield a propellant throughput significantly beyond the first thruster failure mode anticipated for the thruster at $750 \mathrm{~kg}$ propellant throughput.

\section{Thruster Summary}

A summary of the current lifetime assessment for the NEXT thruster components is shown in Table 4 for operation at the peak power throttle point, which typically corresponds to the least capable propellant throughput. A reference to the figures showing how the propellant throughput capability scales across the throttle table for the mechanisms is included in the last column. As testing continues, the models will be increased in fidelity along with this assessment. 
TABLE 4.-TABLE CONTAINING A SUMMARY OF THE NEXT LIFETIME ASSESSMENT

\begin{tabular}{|c|c|c|}
\hline Component & Failure mechanism & $\begin{array}{c}\text { Minimum xenon throughput, } \mathrm{kg} \\
\text { (x } 450 \mathrm{~kg} \text { qualification) }\end{array}$ \\
\hline Discharge cathode & $\begin{array}{l}\text { Insert barium depletion } \\
\text { Orifice plate wear } \\
\text { Keeper wear }\end{array}$ & $\begin{array}{l}1450 \mathrm{~kg}(3.2 \mathrm{x}), \text { Figure } 2 \\
>2000 \mathrm{~kg}(4.4 \mathrm{x}) \\
>2000 \mathrm{~kg}(4.4 \mathrm{x}), \text { Figure } 9\end{array}$ \\
\hline Neutralizer cathode & $\begin{array}{l}\text { Insert barium depletion } \\
\text { Orifice plate wear } \\
\text { Keeper side wear penetration } \\
\text { Cathode orifice clogging }\end{array}$ & $\begin{array}{l}1600 \mathrm{~kg}(3.6 \mathrm{x}), \text { Figure } 10 \\
>850 \mathrm{~kg}(1.9 \mathrm{x}) \\
850 \mathrm{~kg}(1.9 \mathrm{x}) \\
>850 \mathrm{~kg}(1.9 \mathrm{x})\end{array}$ \\
\hline Accelerator optics & $\begin{array}{l}\text { Pit and groove wear / structural failure } \\
\text { Aperture enlargement / electron backstreaming }\end{array}$ & $\begin{array}{l}750 \mathrm{~kg}(1.7 \mathrm{x})^{*}, \text { Figure } 12 \\
>750 \mathrm{~kg}(1.7 \mathrm{x})^{\dagger}\end{array}$ \\
\hline Screen optics & Excessive wear & $>>750 \mathrm{~kg}(1.7 \mathrm{x})$ \\
\hline Optics assembly & An unclearable short & $\begin{array}{l}\text { Mitigation through retention of sputtered } \\
\text { material, thermal cycling of optics, and } \\
\text { power supply for clearing. }\end{array}$ \\
\hline Discharge chamber & $\begin{array}{l}\text { Flake retention of sputtered material } \\
\text { Magnet temperatures }\end{array}$ & $\begin{array}{l}1850 \mathrm{~kg}(4.0 \mathrm{x}) \\
>750 \mathrm{~kg}(1.7 \mathrm{x})\end{array}$ \\
\hline $\begin{array}{l}\text { High voltage } \\
\text { propellant isolators }\end{array}$ & $\begin{array}{l}\text { Degrading voltage standoff from extended operation } \\
\text { at elevated temperature }\end{array}$ & $\begin{array}{l}>>750 \mathrm{~kg}(1.7 \mathrm{x}) \\
\text { Design verification test ongoing. }\end{array}$ \\
\hline
\end{tabular}

The first failure mode predicted on the thruster would be accelerator grid structural failure from pit and groove erosion. The corresponding propellant throughput at full power would be $750 \mathrm{~kg}$ at specific impulses above $2000 \mathrm{sec}$, which well exceeds the $450 \mathrm{~kg}$ throughput requirement by 70 percent. This is supported by the NEXT $2000 \mathrm{hr}$ wear test erosion measurements and LDT in situ measurements. As the specific impulse or thrust decrease, the propellant throughput increases until a specific impulse of $1854 \mathrm{sec}$ and a thrust of $37 \mathrm{mN}$. The propellant throughput before structural failure corresponding to the two lowest power throttle points on the throttle table is below the requirement of $450 \mathrm{~kg}$. However, these throttle points are used only on a small number of missions studied. Based on an analysis of the accelerator grids for the three missions using the three lowest power throttle points, the total depth of groove penetration from the entire mission with the greatest wear is anticipated to be at most 51 percent of the accelerator grid thickness. This would yield the anticipated lifetime of the accelerator grid before structural failure to be about 2 times the mission requirement. There is a degree of uncertainty with the 2-D and 3-D models due to the lack of operational grid gap measurements, beamlet current densities, sputter yield, and redeposition of sputtered material. However, based on erosion measurements from the tests, the analysis can be correlated. The models have not been able to accurately predict the change in electron backstreaming with time. The models predict noticeable decrease in electron backstreaming margin with time at the peak power throttling point, but the tests to date do not show any significant decrease in margin for the NEXT thruster. At best we can consider the models to be conservative with their predictions of lifetime prior to backstreaming, but the degree of uncertainty requires additional work to assure backstreaming does not occur prematurely at other throttling points.

The life-limiter of the discharge cathode is expected to be the impregnated insert. Based on planar impregnated cathodes, the insert is predicted to last over $70 \mathrm{khr}$ at high power, which is about $1450 \mathrm{~kg} \mathrm{Xe}$ throughput and is 3.2 times the qualification requirement.

The other component that wears on the discharge cathode assembly is the keeper. The NEXT PM thruster will be using a graphite keeper, compared to the previous molybdenum keepers, and the wear rate is dramatically reduced. It is predicted that it will be well over $2000 \mathrm{~kg}$ of throughput before the cathode heater and orifice plate are significantly exposed. This prediction is corroborated by the minimal wear on the downstream face of the HiPEP graphite keeper after its $2000 \mathrm{hr}$ test and the NEXT LDT results that show no measurable wear to date of the keeper orifice.

The neutralizer is anticipated to last $77 \mathrm{khr}$ at high power, which is $1600 \mathrm{~kg}$ of Xe throughput, which is 3.6 times the $450 \mathrm{~kg}$ throughput qualification requirement. The neutralizer impregnated insert is 
expected to be the life-limiter for the neutralizer cathode. It is expected that the neutralizer keeper outer radius wear rates on PM thrusters will be significantly reduced from the EM thruster that was tested for $2000 \mathrm{hr}$. It is unlikely, but based on a conservative estimate, a hole could form on the keeper side from beam ions after $850 \mathrm{~kg}$ of propellant throughput, but this still wouldn't constitute a thruster failure. One uncertainty for the neutralizer is orifice clogging. However, this was only documented to have occurred during the NSTAR ELT test. This shouldn't be an issue for the NEXT thruster since the orifice is almost twice the diameter of the NSTAR orifice and operates at higher emission currents.

Additional components such as the high voltage propellant isolators and cathode heaters are either being tested or will be tested to verify lifetime requirements. Electrical shorting of the optics is controlled through retention of sputtered material in the discharge chamber, discharge chamber design minimizing the size of any material sputter from its walls, and the use of thermal cycling or discharge power supply to clear a known short. The magnets will exhibit a lifetime in excess of the NSTAR thruster magnets. After $30,000+\mathrm{hr}$ of operation the magnets on the NSTAR ELT showed no degradation. The magnets will provide an adequate magnetic field beyond the thruster's first anticipated failure mode at $750 \mathrm{~kg}$.

\section{Conclusion}

Lifetime and propellant throughput capability for the NEXT ion thruster and its components based on several models and testing have been presented. The models include evaluation of ion optics wear, discharge and neutralizer cathode wear and insert depletion of low work function material, sputtering that could result in an unclearable high voltage short, evaluation of magnet temperatures, and voltage degradation of propellant isolators. The current assessment predicts that the earliest failure above a specific impulse of $2000 \mathrm{sec}$ would be a structural failure of the accelerator grid after $750 \mathrm{~kg}$ of xenon throughput, $300 \mathrm{~kg}$ beyond or 1.6 to 1.7 times the $450 \mathrm{~kg}$ qualification requirement. Below a specific impulse of $2000 \mathrm{sec}$, the structural failure of the accelerator grid is predicted with less than $750 \mathrm{~kg}$ of propellant throughput, with the two lowest power throttle points below the $450 \mathrm{~kg}$ propellant throughput requirement. However, based on previous mission analysis, accelerator grid downstream erosion on the missions that used these low power throttle points would exhibit a maximum erosion of 51 percent through the accelerator grid thickness. This demonstrates that while the low throttle points individually have propellant throughput capability below $450 \mathrm{~kg}$, the throughput capability is at least twice the mission required. Other failure modes presented are predicted to be in excess of $750 \mathrm{~kg}$ thruster xenon throughput. Modeling has not correctly predicted how electron backstreaming will change with time, but fortunately, the testing at the peak throttle point has shown little change. Additional testing and modeling is necessary to improve the fidelity of this assessment. However, even without this additional testing, there is ample margin to assure the NEXT thruster will meet its qualification requirement of $450 \mathrm{~kg}$.

\section{References}

1. Benson, S.W., Patterson, M.J., Vaughan, D.A., Wilson, A.C., and Wong, B.R., "NASA's Evolutionary Thruster (NEXT) Phase 2 Developmental Status," $41^{\text {st }}$ Joint Propulsion Conference and Exhibit, AIAA-2005-4070, Tucson, AZ, Jul. 10-13, 2005.

2. Patterson, M.J. and Benson, S.W., "NEXT Ion Propulsion System Development Status and Performance," $43^{\text {rd }}$ Joint Propulsion Conference and Exhibit, AIAA-2007-5199, Cincinnati, OH, Jul. 8-11, 2007.

3. Mankins, J.C., “Technology Readiness Levels,” White Paper, Apr. 6, 1995, URL: http://www.hq.nasa.gov/office/codeq/trl/trl.pdf [cited 5 June, 2007].

4. Oh, D., Benson, S., Witzberger, K., and Cupples, M., "Deep Space Mission Applications for NEXT: NASA's Evolutionary Xenon Thruster," 40th Joint Propulsion Conference and Exhibit, AIAA-2004-3806, Fort Lauderdale, FL, Jul. 11-14, 2004. 
5. Sengupta, A., et al., "An Overview of the Results from the 30,000 $\mathrm{Hr}$ Life Test of Deep Space 1 Flight Spare Ion Engine," 40th Joint Propulsion Conference and Exhibit, AIAA-2004-3608, Fort Lauderdale, FL, Jul. 11-14, 2004.

6. Polk, J.E., Anderson, J.R., Brophy, J.R., Rawlin, V.K., Patterson, M.J., Sovey, J., Hamley, J., “An Overview of the Result from the 8200 Hour Wear Test of the NSTAR Ion Thruster, " $35^{\text {th }}$ Joint Propulsion Conference and Exhibit, AIAA-1999-2446, Los Angeles, CA, Jun. 20-24, 1999.

7. Patterson, M.J., Rawlin, V.K., Sovey, J.S., Kussmaul, M.J., and Parkes, J., "2.3 kW Ion Thruster Wear Test," $31^{\text {st }}$ Joint Propulsion Conference and Exhibit, AIAA-95-2516, San Diego, CA, Jul. 10-12, 1995.

8. Polk, J.E., et al., "A 1000-Hour Wear Test of the NASA NSTAR Ion Thruster, " $32^{\text {nd }}$ Joint Propulsion Conference and Exhibit, AIAA-1996-2717, Lake Buena Vista, FL, Jul. 1-3, 1996.

9. Patterson, M.J., et al., "NEXT: NASA's Evolutionary Xenon Thruster Development Status," $39^{\text {th }}$ Joint Propulsion Conference and Exhibit, AIAA-2003-4862, Huntsville, AL, Jul. 20-23, 2003.

10. Emhoff, J.W., Boyd, I.D., "Progress in NEXT Ion Optics Modeling," 40th Joint Propulsion Conference and Exhibit, AIAA-2004-3786, Fort Lauderdale, FL, Jul. 11-14, 2004.

11. Farnell, C.C., Williams, J.D., Wilbur, P. J., "NEXT Ion Optics Simulation Via ffx," $39^{\text {th }}$ Joint Propulsion Conference and Exhibit, AIAA-2003-4869, Huntsville, AL, Jul. 20-23, 2003.

12. Emhoff, J.W., Boyd, I.D., "Grid Erosion Modeling of the NEXT Ion Thruster Optics," $39^{\text {th }}$ Joint Propulsion Conference and Exhibit, AIAA-2003-4868, Huntsville, AL, Jul. 20-23, 2003.

13. Kovaleski, S.D., "Life Model of Hollow Cathode using a Barium Calcium Aluminate Impregnated Tungsten Emitter," $27^{\text {th }}$ International Electric Propulsion Conference, IEPC-01-276, Pasadena, CA, Oct. 14-19, 2001.

14. Polk, J.E., Moore, N.R., Newlin, L.E., Brophy, J.R., and Ebbeler, D.H., "Probabilistic Analysis of Ion Engine Accelerator Grid Life," $23^{\text {rd }}$ International Electric Propulsion Conference, IEPC-93-176, Seattle, WA, Sep. 13-16, 1993.

15. Herman, D., Soulas, G., and Patterson, M., "Status of the NEXT Ion Thruster Long-Duration Test," $43^{\text {rd }}$ Joint Propulsion Conference and Exhibit, AIAA-2007-5272, Cincinnati, OH, Jul. 8-11, 2007.

16. Frandina, M.M., Arrington, L.A., Soulas, G.C., Hickman, T.A., and Patterson, M.J., "Status of the NEXT Ion Thruster Long Duration Test," $41^{\text {st }}$ Joint Propulsion Conference and Exhibit, AIAA2005-4065, Tucson, AZ, Jul. 10-13, 2005.

17. Soulas, G.C., Kamhawi, H., Patterson, M.J., Britton, M.A., and Frandina, M.M., "NEXT Ion Engine 2000 Hour Wear Test Results," 40th Joint Propulsion Conference and Exhibit, AIAA-2004-3791, Fort Lauderdale, FL, Jul. 11-14, 2004.

18. Brophy, J. R., Polk, J. E., and Rawlin, V. K., "Ion Engine Service Life Validation by Analysis and Testing," 32 ${ }^{\text {nd }}$ Joint Propulsion Conference and Exhibit, AIAA-1996-2715, Lake Buena Vista, FL, Jul. 1-3, 1996.

19. Sarver-Verhey, T.R., "Scenario for Hollow Cathode End-of-Life," NASA Contractor Report, NASA/CR-2000-209420, Jan. 2000.

20. Mirtich, M.J., Kerslake, W.R., "Long Lifetime Hollow Cathodes for 30-cm Mercury Ion Thrusters," AIAA International Electric Propulsion Conference, AIAA 76-985, Key Biscayne FL, Nov. 14-17, 1976.

21. Goebel, D.M., et al., "Extending hollow Cathode Life for Electric Propulsion in Long-Term Missions," Space 2004 Conference and Exhibit, AIAA-2004-5911, San Diego, CA, Sep. 28-30, 2004.

22. Dressman, L., "TriService/NASA Cathode Life Test Facility 2002 Annual Report" Crane Division of Naval Surface Warfare Center, Crane, IN, Mar. 2002.

23. Palluel, P., Shroff, A.M., "Experimental Study of Impregnated-Cathode Behavior, Emission and Life," Journal of Applied Physics, Vol. 51 No. 5, 1980, pp. 2894-2902.

24. Doerner, R., Tynan, G.R., Oyerzabal, E., Taylor, K., Goebel, D.M., and Katz, I., "Plasma Surface Interaction Studies for Next-Generation Ion Thrusters," 40th Joint Propulsion Conference and Exhibit, AIAA-2004-4104, Fort Lauderdale, FL, Jul. 11-14, 2004. 
25. Sarver-Verhey, T.R., "28,000 Hour Xenon Hollow Cathode Life Test Results,” 25th International Electric Propulsion Conference, IEPC-97-168, Cleveland, OH, Aug. 24-28, 1997.

26. Polk, J., Marrese, C., Dang, L., Johnson, L., Thornber, B., "Temperature Distribution in Hollow Cathode Emitters," 40th Joint Propulsion Conference and Exhibit, AIAA-2004-4116, Fort Lauderdale, FL, Jul. 11-14, 2004.

27. Polk, J., Personal Communication, November 10, 2004

28. Domonkos, M.T., Foster, J.E., Soulas, G.C., Nakles, M., "Testing and Analysis of N.E.X.T. Ion Engine Discharge Cathode Assembly Wear," $39^{\text {th }}$ Joint Propulsion Conference and Exhibit, AIAA2003-4864, Huntsville, AL, July 20-23, 2003.

29. Doerner, R.P., Whyte, D.G., and Goebel, D.M., "Sputtering Yield Measurements During Low Energy Xenon Plasma Bombardment," Journal of Applied Physics, Vol. 93, No. 9, May 1, 2003, pp. 5816-5823.

30. Williams, J., Colorado State University, Personal Communication, Sep. 2005.

31. Domonkos, M.T., Foster, J.E., and Soulas, G.C., "Wear Testing and Analysis of Ion Engine Discharge Cathode Keeper," Journal of Propulsion and Power, Vol. 21, No. 1, Jan.-Feb. 2005, pp. 102-110.

32. Goebel, D.M., Jameson, K.K., Watkins, R.M., and Katz, I., "Hollow Cathode and Keeper-Region Plasma Measurements Using Ultra-Fast Miniature Scanning Probes," 40th Joint Propulsion Conference and Exhibit, AIAA-2004-3430, Fort Lauderdale, FL, Jul. 11-14, 2004.

33. Sengupta, A., Brophy, J.R., and Goodfellow, K.D., "Status of the Extended Life Test of the Deep Space 1 Flight Spare Ion Engine After 30,352 Hours of Operation," $39^{\text {th }}$ Joint Propulsion Conference and Exhibit, AIAA-2003-4558, Huntsville, AL, Jul. 20-23, 2003.

34. Williams, G.J., Jr., Hickman, T.A., Foster, J.E., and Haag, T.W., "Preliminary Wear Analysis Following a $2000 \mathrm{hr}$ Wear Test of a $20 \mathrm{~kW}$ Class Ion Thruster with Pyrolytic Graphite Ion Optics," The $29^{\text {th }}$ International Electric Propulsion Conference, IEPC-2005-240, Princeton, NJ, Oct. 31Nov. 4, 2005.

35. Britton, M., Soulas, G., Kamhawi, H., Snyder, A., "Destructive Analysis of the NEXT 2000-Hour Wear Test Hollow Cathode Assemblies," National Aeronautics and Space Administration Technical Memo, NASA/TM-2005-213387, Jul. 2005.

36. Kamhawi, H., Soulas, G.C., Patterson, M.J., and Frandina, M.M., "NEXT Ion Engine 2000 hour Wear Test Plume and Erosion Results," 40th Joint Propulsion Conference and Exhibit, AIAA-20043792, Fort Lauderdale, FL, Jul. 11-14, 2004.

37. Van Noord, J.L., Kamhawi, H., McEwen, H.K., "Characterization of a High Current Long Life Hollow Cathode," The $29^{\text {th }}$ International Electric Propulsion Conference, IEPC-2005-321, Princeton, NJ, Oct. 31-Nov. 4, 2005.

38. Kuharski, R.A., Mandell, M.J., Gardner, B.M., Katz, I., and Vaughan, D., "Ion Engine Neutralizer Erosion in Lab and Space," $41^{\text {st }}$ Joint Propulsion Conference and Exhibit, AIAA-2005-3880, Tucson, AZ, Jul. 10-13, 2005.

39. Kovaleski, S.D., Patterson, M.J., Soulas, G.C., and Sarver-Verhey, T.R., "A Review of Testing Hollow Cathodes for the International Space Station Plasma Contactor," $27^{\text {th }}$ International Electric Propulsion Conference, IEPC-01-271, Pasadena, CA, Oct. 14-19, 2001.

40. Patterson, M.J., Verhey, T.R., Soulas, G., and Zakany, J., "Space Station Cathode Design, Performance, and Operating Specifications," $25^{\text {th }}$ International Electric Propulsion Conference, IEPC-97-170, Aug. 24-28, 1997.

41. Piñero, L.R. and Sovey, J.S., "NEXT Thruster Component Verification Testing," $43^{\text {rd }}$ Joint Propulsion Conference and Exhibit, AIAA-2007-5276, Cincinnati, OH, Jul. 8-11, 2007.

42. Soulas, G.C., "Improving the Total Impulse Capability of the NSTAR Ion Thruster with ThickAccelerator-Grid Ion Optics," $27^{\text {th }}$ International Electric Propulsion Conference, IEPC-01-081, Pasadena, CA, Oct. 14-19, 2001. 
43. Soulas, G.C., Haag, T.W., and Patterson, M.J., "Performance Evaluation of $40 \mathrm{~cm}$ Ion Optics for the NEXT Ion Engine," $38^{\text {th }}$ Joint Propulsion Conference and Exhibit, AIAA-2002-3834, Indianapolis, IN, Jul. 7-10, 2002.

44. Anderson, J.R., Katz, I., and Goebel, D., "Numerical Simulation of Two-Grid Ion Optics Using a 3D Code," 40th Joint Propulsion Conference and Exhibit, AIAA-2004-3782, Fort Lauderdale, FL, Jul. 11-14, 2004.

45. Malone, S.P. and Soulas, G.C., "Computational Ion Optics Design Evaluation," 40th Joint Propulsion Conference and Exhibit, AIAA-2004-3784, Fort Lauderdale, FL, Jul. 11-14, 2004.

46. Diaz, E.M. and Soulas, G.C., "Grid Gap Measurement for NSTAR Ion Thruster," The $29^{\text {th }}$ International Electric Propulsion Conference, IEPC-2005-244, Princeton, NJ, Oct. 31-Nov. 4, 2005.

47. Monheiser, J.M. and Wilbur, P.J., "Effect of Design and Operating Conditions on Accelerator-Grid Impingement Current," $23^{\text {rd }}$ International Electric Propulsion Conference, IEPC-93-174, Seattle, WA, Sep. 13-16, 1993.

48. Pullins, S., Dressler, R.A., Chiu, Y.-H., and Levandier, D.J., "Ion Dynamics in Hall Effect and Ion Thrusters: $\mathrm{Xe}^{+}+\mathrm{Xe}$ Symmetric Charge Transfer," $38^{\text {th }}$ Aerospace Sciences Meeting \& Exhibit, AIAA-2000-0603, Reno, NV, Jan. 10-13, 2000.

49. Duchemin, O.B., "An Investigation of Ion Engine Erosion by Low Energy Sputtering,” Ph.D. Dissertation, California Institute of Technology, Pasadena, CA, 2001.

50. Soulas, G.C. and Patterson, M. J, "NEXT Ion Thruster Performance Dispersion Analysis," $43^{\text {rd }}$ Joint Propulsion Conference and Exhibit, AIAA-2007-5213, Cincinnati, OH, Jul. 8-11, 2007.

51. Anderson, J.R., Sengupta, A., and Brophy, J.R., "Post-Test Analysis of the Deep Space One Spare Flight Thruster Ion Optics," 40th Joint Propulsion Conference and Exhibit, AIAA-2004-3610, Fort Lauderdale, FL, Jul. 11-14, 2004.

52. Hickman, T.A., et al., "Overview of Diagnostics for the NEXT Long Duration Test," $41^{\text {st } J o i n t ~}$ Propulsion Conference and Exhibit, AIAA-2005-4064, Tucson, AZ, Jul. 10-13, 2005.

53. Malone, S.P., "Investigation of NEXT Ion Optics Erosion Processes Using Computational Modeling," $52^{\text {nd }}$ Joint Army-Navy-NASA-Air Force (JANNAF) Propulsion Meeting (JPM), Monterey, CA, Dec. 2005.

54. Sovey, J.S., Dever, J.A., and Power, J.L., "Retention of Sputtered Molybdenum on Ion Engine Discharge Chamber Surfaces," $27^{\text {th }}$ International Electric Propulsion Conference, IEPC-01-086, Pasadena, CA, Oct. 14-19, 2001.

55. Power, J.L. and Hiznay, D.J., "Solutions for Discharge Chamber Sputtering and Anode Deposit Spalling in Small Mercury Ion Thruster," NASA TM X-71675, Mar. 1975.

56. Polk, J.E., et al., "Performance of the NSTAR Ion Propulsion System on the Deep Space One Mission," 39 ${ }^{\text {th }}$ AIAA Aerospace Sciences Meeting, AIAA-2001-0965, Reno, NV, Jan. 8-11, 2001.

57. Goodfellow, K.D., Ganapathi, G.B., and Stocky, J.F., "An Experimental and Theoretical Analysis of the Grid Clearing Capability of the NSTAR Ion Propulsion System," $35^{\text {th }}$ Joint Propulsion Conference and Exhibit, AIAA-1999-2859, Los Angeles, CA, Jun. 20-24, 1999.

58. Anderson, J.R., Vaughn, D., and Fitzgerald, D., "Experimental and Theoretical Analysis for Designing a Grid Clearing System for the NEXT Ion Propulsion System," $41^{\text {st }}$ Joint Propulsion Conference and Exhibit, AIAA-2005-3866, Tucson, AZ, Jul. 10-13, 2005.

59. Van Noord, J., "NEXT Ion Thruster Thermal Model," $43^{\text {rd }}$ Joint Propulsion Conference and Exhibit, AIAA-2007-5218, Cincinnati, OH, Jul. 8-11, 2007.

60. Christensen, J.A., et al., "Design and Fabrication of a Flight Model $2.3 \mathrm{~kW}$ Ion Thruster for the Deep Space 1 Mission," 34 ${ }^{\text {th }}$ Joint Propulsion Conference and Exhibit, AIAA-1998-3327, Jul. 1998.

61. Sovey, J.S., Zakany, J.S. and Manzella, D.H., "NSTAR High Voltage Propellant Isolator Test," NASA/TM-2004-212921, Feb. 2004.

62. Hoskins, W.A., et al., "Development of a Prototype Model ion Thruster for the NEXT System," 40th Joint Propulsion Conference and Exhibit, AIAA-2004-4111, Fort Lauderdale, FL, Jul. 11-14, 2004.

63. Hoskins, W.A., et al., "Overview of the NEXT Ion Propulsion System Program at Aerojet," $41^{\text {st }}$ Joint Propulsion Conference and Exhibit, AIAA-2005-3885, Tucson, AZ, Jul. 10-13, 2005. 


\begin{tabular}{|c|c|c|}
\hline \multicolumn{2}{|c|}{ REPORT DOCUMENTATION PAGE } & $\begin{array}{l}\text { Form Approved } \\
\text { OMB No. 0704-0188 }\end{array}$ \\
\hline \multicolumn{3}{|c|}{ 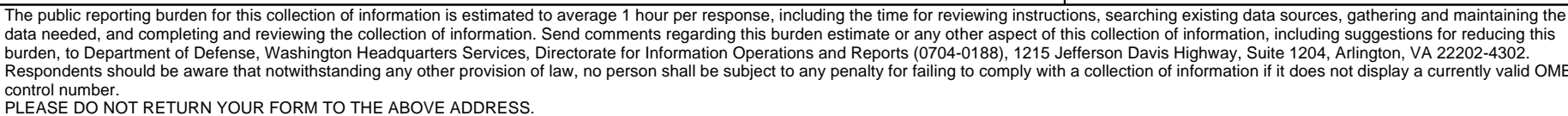 } \\
\hline $\begin{array}{l}\text { 1. REPORT DATE (DD-MM-YYYY) } \\
01-11-2010\end{array}$ & $\begin{array}{l}\text { 2. REPORT TYPE } \\
\text { Technical Memorandum }\end{array}$ & 3. DATES COVERED (From - To) \\
\hline \multirow{3}{*}{\multicolumn{2}{|c|}{$\begin{array}{l}\text { 4. TITLE AND SUBTITLE } \\
\text { Lifetime Assessment of the NEXT Ion Thruster }\end{array}$}} & 5a. CONTRACT NUMBER \\
\hline & & 5b. GRANT NUMBER \\
\hline & & 5c. PROGRAM ELEMENT NUMBER \\
\hline \multirow{3}{*}{\multicolumn{2}{|c|}{$\begin{array}{l}\text { 6. AUTHOR(S) } \\
\text { Van Noord, Jonathan, L. }\end{array}$}} & 5d. PROJECT NUMBER \\
\hline & & 5e. TASK NUMBER \\
\hline & & $\begin{array}{l}\text { 5f. WORK UNIT NUMBER } \\
\text { WBS } 346620.04 .05 .03 .13\end{array}$ \\
\hline \multicolumn{2}{|c|}{$\begin{array}{l}\text { 7. PERFORMING ORGANIZATION NAME(S) AND ADDRESS(ES) } \\
\text { National Aeronautics and Space Administration } \\
\text { John H. Glenn Research Center at Lewis Field } \\
\text { Cleveland, Ohio 44135-3191 }\end{array}$} & $\begin{array}{l}\text { 8. PERFORMING ORGANIZATION } \\
\text { REPORT NUMBER } \\
\text { E-17491 }\end{array}$ \\
\hline \multirow{2}{*}{\multicolumn{2}{|c|}{$\begin{array}{l}\text { 9. SPONSORING/MONITORING AGENCY NAME(S) AND ADDRESS(ES) } \\
\text { National Aeronautics and Space Administration } \\
\text { Washington, DC 20546-0001 }\end{array}$}} & $\begin{array}{l}\text { 10. SPONSORING/MONITOR'S } \\
\text { ACRONYM(S) } \\
\text { NASA }\end{array}$ \\
\hline & & $\begin{array}{l}\text { 11. SPONSORING/MONITORING } \\
\text { REPORT NUMBER } \\
\text { NASA/TM-2010-216915 }\end{array}$ \\
\hline \multicolumn{3}{|c|}{$\begin{array}{l}\text { 12. DISTRIBUTIONIAVAILABILITY STATEMENT } \\
\text { Unclassified-Unlimited } \\
\text { Subject Category: } 20 \\
\text { Available electronically at http://gltrs.grc.nasa.gov } \\
\text { This publication is available from the NASA Center for AeroSpace Information, 443-757-5802 }\end{array}$} \\
\hline
\end{tabular}

\section{SUPPLEMENTARY NOTES}

\section{ABSTRACT}

Ion thrusters are low thrust, high specific impulse devices with required operational lifetimes on the order of 10,000 to $100,000 \mathrm{hr}$. The NEXT ion thruster is the latest generation of ion thrusters under development. The NEXT ion thruster currently has a qualification level propellant throughput requirement of $450 \mathrm{~kg}$ of xenon, which

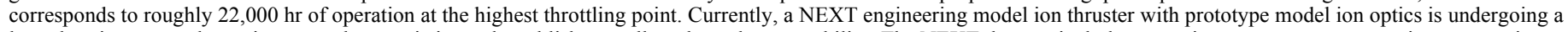

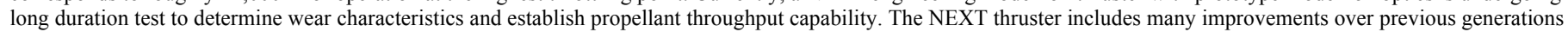
of ion thrusters, but two of its component improvements have a larger effect on thruster lifetime. These include the ion optics with tighter tolerances, a masked region and better gap control, and the discharge cathode keeper material change to graphite. Data from the NEXT 2000 hr wear test, the NEXT long duration test, and further analysis is used to determine the expected lifetime of the NEXT ion thruster. This paper will review the predictions for all of the anticipated failure mechanisms. The mechanisms will

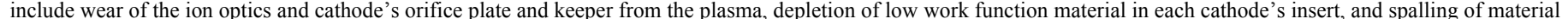

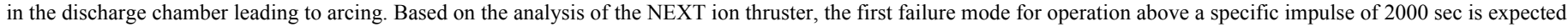

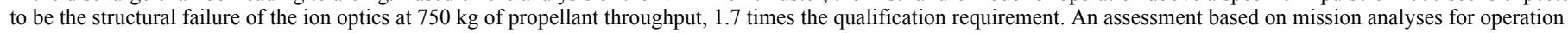
below a specific impulse of $2000 \mathrm{sec}$ indicates that the NEXT thruster is capable of double the propellant throughput required by these missions.

\section{SUBJECT TERMS}

Ion thruster; Ion optics; Hollow cathodes

\begin{tabular}{|l|l|l|c|}
\hline \multicolumn{2}{|l|}{ 16. SECURITY CLASSIFICATION OF: } & $\begin{array}{l}\text { 17. LIMITATION OF } \\
\text { ABSTRACT }\end{array}$ & $\begin{array}{l}\text { 18. NUMBER } \\
\text { OF } \\
\text { PAGES }\end{array}$ \\
\begin{tabular}{|l|l|l|} 
a. REPORT \\
U
\end{tabular} & $\begin{array}{l}\text { b. ABSTRACT } \\
\text { C. THIS } \\
\text { PAGE } \\
\text { U }\end{array}$ & UU & 34 \\
\hline
\end{tabular}

\begin{tabular}{|l|} 
19a. NAME OF RESPONSIBLE PERSON \\
STI Help Desk (email:help@sti.nasa.gov) \\
\hline 19b. TELEPHONE NUMBER (include area code) \\
443-757-5802
\end{tabular}

Standard Form 298 (Rev. 8-98) Prescribed by ANSI Std. Z39-18 

